\title{
Automatic balance mechanisms for notional defined contribution pension systems guaranteeing social adequacy and financial sustainability: an application to the Italian pension system
}

\author{
Pierre Devolder $^{1} \cdot$ Susanna Levantesi ${ }^{2}$ (D) $\cdot$ Massimiliano Menzietti $^{3}$
}

Accepted: 26 September 2020 / Published online: 14 October 2020

(c) The Author(s) 2020

\begin{abstract}
Since the mid 1990s some European countries (including Italy) implemented a Notional Defined Contribution (NDC) pension system. Such a system is based on pay-as-you-go funding, while the pension amount is a function of the individual lifelong contribution. Despite many appealing features, the NDC system presents some drawbacks: first, it is vulnerable to demographic and economic shocks compromising the financial sustainability; second, it could fail to guarantee adequate pension benefits to pensioners. In order to reduce the first limit, automatic balance mechanisms (ABMs) have been proposed in literature and also implemented in Sweden, while solutions that combine financial sustainability and social adequacy have been applied only in a pay-as-you-go point system. The aim of this paper is to insert into the Italian NDC architecture ABMs that preserve social adequacy under financial sustainability constraints. Godinez-Olivares et al. (Insur Math Econ 69:117-126, 2016) built ABMs for a Defined Benefit pension system using nonlinear optimization techniques to calculate the optimal paths of the control variables representing the main drivers of the system: contribution rate, retirement age and indexation of pensions. Following this line of research, we have developed a nonlinear optimization model for the Italian NDC system based on three control variables: pensions indexation, notional rate and contribution rate. The objective function considers both social adequacy and contribution rate sustainability, under liquidity and sustainability constraints. In the numerical application we apply the model to the Italian pension system and test the sensitivity of the results to different economic scenarios and objective function parameters.
\end{abstract}

Keywords Notional Defined Contribution pension systems · Automatic balance mechanisms $\cdot$ Social adequacy $\cdot$ Financial sustainability $\cdot$ Optimization

\footnotetext{
Susanna Levantesi

susanna.levantesi@uniroma1.it

1 Université Catholique de Louvain (UCL), Louvain-La-Neuve, Belgium

2 Sapienza University of Rome, Viale Regina Elena 295-G, 00141 Rome, Italy

3 University of Calabria, Rende, Italy
} 


\section{Introduction}

Traditional pension schemes in social security usually combine a Defined Benefit structure (DB) with a pay-as-you-go mechanism (PAYG). This classical architecture aims at creating an intergenerational solidarity while guaranteeing a well-defined level of living standard for retirees. However, the aging phenomena, caused by a significant increase in longevity and a decrease in fertility, has deeply threatened these schemes. Therefore, many countries have adapted different reforms in order to restore the financial sustainability. Among these strategies, the NDC mechanism has been proposed as a credible alternative (Gronchi and Nisticò 2006; Holzmann 2017).

NDC is based on a combination of pay-as-you-go (PAYG) financing and a pension formula mimicking financial defined contribution schemes: the contributions are accumulated until retirement in an account using a rate of return. At retirement age, the account is converted into a lifelong annuity. The scheme is notional because of the underlying PAYG mechanism: the accounts are virtual and not invested in the financial markets; they are just used for computation of the benefits. The main parameters of a NDC scheme are: the contribution rate (fixed due to the DC structure), the normal retirement age, the notional rate (virtual rate of return given to the account), the indexation parameter (adaptation of the benefits after retirement), the conversion factor (transformation of the notional account into a lifetime annuity) and the eventual automatic adjustment mechanism (eventual ex post corrections on the notional rate and/or the indexation parameter). This philosophy has been successfully implemented in different European countries (Sweden, Italy, Poland, Latvia. . .) (ChlońDomińczak et al. 2012). The characteristics of these NDC systems can be different from one country to another (see Table 1 in the "Appendix A" comparing four countries).

Undoubtedly, NDC has many important advantages with respect to classical DB schemes (Holzmann 2017). From an individual point of view, NDCs can be considered as actuarially fair because of the direct link between the contributions and the pension paid after retirement (Palmer 2006) and the DC nature should induce financial sustainability on a long-term basis. Despite these appealing characteristics, NDC has serious drawbacks. If theoretically the system is in equilibrium in a steady state (with constant demographical and economic conditions), the method cannot automatically guarantee financial sustainability in dynamic realistic conditions (Valdés-Prieto 2000). Therefore, adjustment mechanisms are necessary to restore equilibrium.

Automatic Balance mechanisms are techniques introduced in a public pension scheme in order to automatically correct its parameters; the purpose is to avoid waiting for political interventions (Vidal-Meliá et al. 2009). Different kinds of automatic balance mechanisms have been proposed in the literature for NDC schemes (see e.g. Knell 2010; Alonso-García et al. 2018). In Sweden for instance, automatic balance mechanisms have been put in place: automatic adjustment rules are applied each year to the notional rate and the indexation rate of pensions, depending on the solvency situation (Settergren 2001). However, all these mechanisms generally remain in a strict DC environment. The adjustments correct only the level of present and future benefits and the contribution rate remains unchanged.

This logic seems coherent with the DC characteristics of NDC. Nevertheless, in an aging world, it could fail to guarantee adequate pension benefits to pensioners. If financial sustainability is a key issue for a social security pension scheme, its social adequacy is also important. In this perspective, pure NDC with mechanisms adjusting only the benefit side can be seen as an unfair intergenerational solution. From a general point of view, DB and DC are extreme cases with respect to adaptation to external risks: DB is focused on social 
adequacy while DC is concerned with financial sustainability. Intermediate compromises exist where a risk sharing is applied between all the generations [see for instance Musgrave (1981)]: retirees accept some adaptation of their benefit level while active people accept some variability of their contributions. Financial sustainability is then combined with social adequacy. This philosophy has been successfully applied in the context of a PAYG points system (Schokkaert et al. 2018; Devolder and de Valeriola 2019).

The purpose of this paper is to introduce such a logic inside the NDC architecture. The basic mechanism of NDC remains unchanged but the contribution rate can fluctuate over time. More precisely, we develop an automatic balance mechanism using nonlinear optimization to guarantee both social adequacy and financial sustainability in NDC systems. The proposed $\mathrm{ABM}$ is based on three decision variables: the benefit indexation rate (effect on paid pensions), the notional rate (effect on the level of future pensions) and the contribution rate (effect on the funding).

The closest contribution in the literature to our paper is from Gannon et al. (2016), that developed ABMs in a DB system, introducing a nonlinear optimization problem based on three decision variables: contribution rate, indexation of pensions and retirement age. Following these authors, we consider the contribution rate and the indexation of pensions, but also the notional rate as decision variables, including lower and upper bounds and smooth constraints, but in the context of a NDC system. In our analysis, we introduce an optimization problem in order to monitor the control variables and generate a mechanism preserving the adequacy of the system under financial sustainability constraints. Otherwise, in Gannon et al. (2016), the objective function in the optimization problem aims to restore the pension system's sustainability through the actuarial balance.

It is worth noting that in our model the inclusion of a control variable operating on contribution rate can be considered a novelty in the current debate on adjustment mechanisms in NDC systems. To test the effectiveness of the proposed ABMs, we provide a numerical illustration based on the Italian pension system, showing how the optimal paths of the control variables change under different economic scenarios.

The existing literature on the optimization techniques in pension systems rather than involving PAYG systems, mainly concerns pension funds and their asset allocation (or asset liability management), such as dynamic decision problems on allocation of the assets, the contributions and the indexation of future payments. Some interesting contributions involving optimization techniques in pension systems have been provided by Battocchio et al. (2007) that analyze the pension funds optimal asset allocation maximizing the expected utility of its surplus (difference between total wealth and retrospective reserve) and Klein Haneveld et al. (2010) that study the pension fund strategic asset liability management problem considering long-term solvency goals and short-term constraints on the ratio of assets over liabilities (funding ratio) specified in probabilistic terms. Finally, Kopa et al. (2018) propose a model for an employee optimal pension allocation from a retirement perspective under stochastic dominance constraints, applying a multistage stochastic programming approach.

The paper is organized as follows. Section 2 presents the basics of the NDC system and the PAYG mechanism. In Sect. 3, we propose a new automatic balance mechanism based on three control variables (notional rate, indexation rate and contribution rate), while in Sect. 4 we illustrate the optimization problem for calculating the optimal paths of the control variables. A numerical illustration is presented in Sects. 5 and 6 lays out this paper's conclusion. 
Fig. 1 Multiple state model for pension system

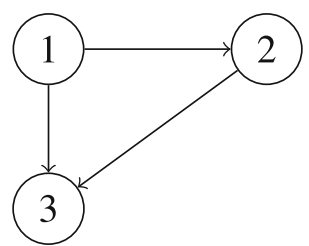

\section{The model for a notional defined contribution system}

This section presents the main demographic and financial assumptions applied to a NDC system. We describe the determinants of the evolution of the active and beneficiary population (Sect. 2.1), the evolution of contribution and benefits (Sect. 2.2), and the features of a PAYG funding system (Sect. 2.3).

\subsection{Active and beneficiary population}

We consider a pension system paying only retirement pensions, disregarding invalidity benefits, survivor benefits and withdrawals. Therefore, we can represent the evolution of the active and beneficiary population by a multiple state model, where $\{X(\tau) ; \tau=0,1,2, \ldots, T\}$ is the random state of an individual belonging to the system at time $\tau$. The model has a finite state space $X=\{1=$ active, $2=$ pensioner, $3=$ dead $\}$ and a set of transitions according to Fig. 1 .

We assume that all the transition probabilities depend on age and time, while are independent from the past service duration. ${ }^{1}$ Hence, the process can be modeled by a timeinhomogeneous Markov chain in a discrete time, with $[0, T]$ the fixed finite time horizon.

The transition probabilities of a life being in state $j$ at age $x+\tau$, given that the life is in state $i$ at age $x$, are defined as follows:

$$
{ }_{\tau} p^{i j}(x, t)=\mathbb{P}\{X(t+\tau)=j \mid X(t)=i\} \quad i, j \in X, i \neq j,
$$

While the probability of a life being in state $i$ at age $x$ to remain in the same state up to age $x+\tau$ is:

$$
{ }_{\tau} p^{i i}(x, t)=\mathbb{P}\{X(t+z)=i \text { for all } z \in[0, \tau], X(t)=i\}
$$

We assume that each transition is at the beginning of the year. We denote $N^{i}(x, t)$ and $Z^{i}(x, t)$ as the number of lives and the new entrants in state $i$ at age $x$ at time $t$, respectively. Therefore, the total population in the state $i$ at time $t$ is given by:

$$
N^{i}(t)=\sum_{x} N^{i}(x, t)
$$

While, the total new entrants in the state $i$ at time $t$ are given by:

$$
Z^{i}(t)=\sum_{x} Z^{i}(x, t)
$$

Typically, the future evolution of new entrants in active state can be modeled in three different ways (Iyer 1999): the first one assumes given the age distribution of new entrants; the second one supposes given the evolution of the total number of actives by age, $N^{1}(x, t)$ (e.g. based on

1 Therefore, the eligibility for retirement pension does not depend on the years of service. 
labour force or general population projections); the third one assumes known the growth rate of total active population, $\rho(t)$, equally affecting all groups of contributors, and the relative age distribution of the new entrants in the active state, $d_{z}(x, t)$. In the last two cases, the age distribution of new actives for each projection year is indirectly deduced.

Regarding the first case, it is unusual to assume known the age distribution of new entrants over the forecasting horizon (Iyer 1999). Following the prevalent literature (e.g. Gronchi and Nisticò 2006; Alonso-García et al. 2018), we consider the third approach: given the initial total active population, $N^{1}(0)$, and its growth rate, $\rho(t)$, the total active population at time $t$ is:

$$
N^{1}(t)=N^{1}(t-1)(1+\rho(t))
$$

The total new actives are described by the following equation:

$$
Z^{1}(t)=N^{1}(t)-\sum_{x} N^{1}(x-1, t-1) p^{11}(x-1, t-1)
$$

While, the number of new entrants by age, $Z^{1}(x, t)$, is obtained by:

$$
Z^{1}(x, t)=Z^{1}(t) d_{z}(x, t)
$$

Therefore, the active population aged $x$ at time $t$ is calculated by:

$$
N^{1}(x, t)=N^{1}(x-1, t-1) p^{11}(x-1, t-1)+Z^{1}(x, t)
$$

Equation 2.8 can be rewritten as follows:

$$
N^{1}(x, t)=N^{1}(x-t, 0)_{t} p^{11}(x-t, 0)+\sum_{h=0}^{T^{\prime}} Z^{1}(x-h, t-h)_{h} p^{11}(x-h, t-h)
$$

where $T^{\prime}=\min (t-1, x-\alpha), x-t \geq \alpha$ and $\alpha$ the minimum age of new entrants.

Note that $N^{1}(x-t, 0)_{t} p^{11}(x-t, 0)$ is the proportion of the initial active population still in the active state at time $t$, while the second term represents the new generations of actives.

The pensioners' population aged $x$ at time $t$ is calculated by:

$$
N^{2}(x, t)=N^{2}(x-1, t-1) p^{22}(x-1, t-1)+Z^{2}(x, t)
$$

where $Z^{2}(x, t)=N^{1}(x-1, t-1) p^{12}(x-1, t-1)$ are the new pensioners aged $x$ in year $t$. Note that the probability $p^{12}(x-1, t-1)$ takes into account both the pension system rules and the retirement propensity, and then it is zero before the minimum retirement age and one at the maximum retirement age.

Equation 2.10 can be rewritten as follows:

$$
N^{2}(x, t)=N^{2}(x-t, 0)_{t} p^{22}(x-t, 0)+\sum_{h=0}^{T^{\prime \prime}} Z^{2}(x-h, t-h)_{h} p^{22}(x-h, t-h)
$$

where $T^{\prime \prime}=\min (t-1, x-\beta), x-t \geq \beta$ and $\beta$ the minimum age of retirements.

Note that $N^{2}(x-t, 0) t p^{22}(x-t, 0)$ is the proportion of the initial beneficiaries still in the state of pensioner at time $t$, while the second term represents the new generations of pensioners.

The new deaths at age $x$ occurring in the year $t$ are calculated by the following equation:

$$
Z^{3}(x, t)=N^{1}(x-1, t-1) p^{13}(x-1, t-1)+N^{2}(x-1, t-1) p^{23}(x-1, t-1)
$$




\subsection{Contribution and benefits}

We assume that individual wage depends only on age and time, and not on seniority. Therefore, denoted $s(x, t, i)$ as the wage for an individual $i$ aged $x$ at time $t$, individuals with same age $x$ in year $t$ have the same individual wage, ${ }^{2}$ i.e. $s(x, t, i)=s(x, t) \forall i$ independently from their past service duration. We denote $\xi(t)$ as the growth rate of individual wage from $t-1$ to $t$ such that:

$$
s(x, t)=s(x, t-1)[1+\xi(t)]
$$

Under this framework, the total wage earned by the active population aged $x$ in the year $t$ is derived by:

$$
S(x, t)=N^{1}(x, t) s(x, t)
$$

While, the amount of total wage earned by the active population in the year $t$ is:

$$
S(t)=\sum_{x} S(x, t)
$$

Furthermore, the average wage in year $t$ is calculated as:

$$
s(t)=\frac{S(t)}{N^{1}(t)}=\frac{\sum_{x} N^{1}(x, t) s(x, t)}{\sum_{x} N^{1}(x, t)}
$$

Note that $s(t)$ is the weighted average of the individual wage, $s(x, t)$, where the weights are the proportion of actives aged $x$ to the total active population in year $t$. Moreover, if the pension system is in a steady state, Eqs. 2.13 and 2.16 imply that:

$$
s(t)=s(t-1)[1+\xi(t)]
$$

When the pension system is in a steady state, combining Eqs. 2.5, 2.16 and 2.17, the amount of total wage evolves as follows:

$$
S(t)=S(t-1)[1+\xi(t)][1+\rho(t)]
$$

The total contribution paid by the active population aged $x$ in the year $t$ is:

$$
C(x, t)=c(t) S(x, t)
$$

Where $c(t)$ is the contribution rate characterizing the pension system in the year $t$ and the amount of total contribution paid by the active population in the year $t$ is:

$$
C(t)=\sum_{x} C(x, t)=c(t) S(t)
$$

By definition, in a NDC system the contribution rate should be constant, $c(t)=c$ for all $t$, and the pension benefit at retirement depends on the total contributions paid by the individual during his working life. These contributions are virtually accumulated in an individual notional account and converted in an annuity at retirement. The individual account is remunerated each year $t$ at a notional rate of return, $g(t)$, that can be chosen in different ways (see e.g. Holzmann 2017):

- equal to the growth rate of the total wage in the year $t$, that coincides with the growth rate of contribution. When the system reaches the steady state, the notional rate becomes: $[1+\xi(t)][1+\rho(t)]-1$; therefore it is affected by both wage and population evolution.

${ }^{2}$ It is the wage relevant to the social security pension scheme for full-time work. 
This choice guarantees that the NDC system is sustainable in both a steady state and a semi steady state (where the growth rate of actives is constant, but the growth rate of wages could vary). For this reason, such a rate is also known as "natural rate"(Valdés-Prieto 2000) or "canonical rate"(Gronchi and Nisticò 2006).

- equal to the growth of the contribution base per capita that increase at the same rate of the individual wage. This is the rate applied in Sweden (see e.g. Alonso-García et al. 2018).

- as a function of the growth rate of notional GDP. For example, in Italy it is equal to the five-year GDP growth average rate. Note that this notional rate "can be equal to the wage bill growth rate only if the distributive shares in GDP remain constant"(Gronchi and Nisticò 2006).

Due to the assumption of the individual wage, the individual notional account for an individual $i$ aged $x$ at the end of year $t$ evolves as follows:

$$
m(x, t, i)=[m(x-1, t-1, i)+c(t) s(x, t)][1+g(t)]
$$

The total accumulated notional capital at the end of year $t$ for the actives aged $x$ is equal to:

$$
M(x, t)=\sum_{i \in N^{1}(x, t)} m(x, t, i)
$$

and evolves as follows ${ }^{3}$ :

$$
M(x, t)=\left[M(x-1, t-1) p^{11}(x-1, t-1)+C(x, t)\right][1+g(t)]
$$

At the end of working life, the initial amount of pension is determined by dividing the accumulated notional capital to an annuity rate specific for each age $x$ and time $t, \ddot{a}(x, t)$, calculated as:

$$
\ddot{\mathrm{a}}(x, t)=\sum_{h=0} h p^{22 *}(x, t) \cdot \prod_{k=t}^{t+h}\left[\frac{1+\lambda^{*}(k)}{1+g^{*}(k)}\right]
$$

where $\lambda^{*}(t)$ is the ex-ante pension indexation, ${ }^{4} g^{*}(t)$ is the ex-ante notional rate (or discount) and ${ }_{h} p^{22 *}(x, t)$ is the ex-ante survival probability of a pensioner aged $x$ at time $t$ for $h$ years. ${ }^{5}$ Note that the evaluation of $\ddot{\mathrm{a}}(x, t)$ requires assumptions on all the above variables.

Equation 2.24 can be rewritten as a function of a discounting rate, $j^{*}(k)=\frac{1+\lambda^{*}(k)}{1+g^{*}(k)}-1$, summarizing the pension indexation and the notional rate, as follows:

$$
\ddot{\mathrm{a}}(x, t)=\sum_{h=0} h p^{22 *}(x, t) \cdot \prod_{k=t}^{t+h}\left[1+j^{*}(k)\right]
$$

\footnotetext{
${ }^{3}$ Note that we consider mortality before retirement in the evolution of the population (2.12), but not in the formula of the total accumulated notional capital (2.23), automatically creating a survival dividend. Moreover, we do not take into account inheritance gains: this aspect is not relevant in the numerical illustration because we assume no mortality before retirement age. Inheritance gains are actually redistributed in Sweden, while not in Italy.

${ }^{4}$ We can observe that the pension indexation differs from one country to another. For example, the pension benefits are indexed to the inflation rate in Italy and in Latvia, while it is given by the difference between the consumer price index and $1.6 \%$ in Sweden and by a combination of the consumer price index and the wage increase in Poland (see Gronchi and Nisticò (2006) for Chloń-Domińczak et al. (2012) for the other countries).

${ }^{5}$ Note that in the Italian pension system the calculation of ä $(x, t)$ only takes into account for the mortality improvement up to time $t$ and not its future evolution during the pension payment.
} 
Once defined the individual notional account and the annuity rate, the initial pension benefit paid in advance to a new pensioner aged $x$ in the year $t$ is calculated as:

$$
b_{z}(x, t, i)=\frac{m(x, t, i)}{\ddot{a}(x, t)}
$$

While, the total amount of pension paid to the new retirees is given by:

$$
B_{z}(x, t)=\sum_{i \in Z^{2}(x, t)} b_{z}(x, t, i)
$$

The total pensions paid to retirees aged $x$ in the year $t$ are then calculated as:

$$
B(x, t)=B(x-1, t-1) p^{22}(x-1, t-1)[1+\lambda(t-1)]+B_{z}(x, t)
$$

Note that $\lambda$ is the effective pension indexation experienced by the pensioners that could differ from the estimated value $\lambda^{*}$.

Finally, the amount of total pensions paid to retirees in the year $t$ is derived by:

$$
B(t)=\sum_{x} B(x, t)
$$

\subsection{The PAYG system}

A PAYG system is said to be perfectly balanced when the income from contributions matches the expenditure on pensions:

$$
N^{1}(t) \cdot c(t) \cdot s(t)=N^{2}(t) \cdot b(t)
$$

where $b(t)=\frac{B(t)}{N^{2}(t)}$ is the average pension. The fixed contribution rate $c(t)$ not always guarantees the system's equilibrium. Therefore, we define $\hat{c}(t)$ as the PAYG contribution rate satisfying the equilibrium equation 2.30 :

$$
\hat{c}(t)=\frac{N^{2}(t)}{N^{1}(t)} \cdot \frac{b(t)}{s(t)}
$$

Denoting $D(t)=\frac{N^{2}(t)}{N^{1}(t)}$ as the dependency ratio and $r(t)=\frac{b(t)}{s(t)}$ as the benefit ratio in the year $t$, the equilibrium equation can be rewritten as:

$$
\hat{c}(t)=D(t) \cdot r(t)
$$

By definition, in a NDC system the contribution rate should be constant, therefore in the case of a variation of the dependency ratio (benefit ratio), the system should be automatically adjusted by changing the benefit ratio (dependency ratio).

First of all, it should be noticed that there is no clear definition of sustainability. As pointed out by Knell et al. (2006), "fiscal policies are sustainable if they can be continued indefinitely; unsustainable policies will ultimately have to be modified. . . while there is no unique theoretical benchmark of sustainability, all definitions do imply that an ever-increasing debt ratio is not sustainable." Applied in the area of a pensions system, sustainability could be defined as "a position where there is no need to increase the contribution rate in the future" (see Vidal-Meliá 2010). Such a definition could be easily applied to NDC systems but not to DB ones.

With regard to the difference between sustainability and solvency, the concept of solvency is typical of the private insurance sector and refers to the "ability of a pension scheme's assets 
to meet the scheme's liabilities indicator" (Gannon et al. 2016). Concerning the use of liquidity and/or solvency indicators, Boado-Penas et al. (2008) observe that often annual cash-flow deficit/surplus are considered as "solvency indicator, despite the fact that it is only a liquidity indicator". A PAYG system could experience periods with cash-flow surpluses along with decreasing solvency ratio.

We measure the liquidity of the system in the year $t$ by the unfunded liabilities $(U L)$, defined as the difference between the pension benefits paid to pensioners and the contribution earned by actives:

$$
U L(t)=B(t)-C(t)
$$

Note that the unfunded liabilities over time imply the accumulation of a reserve fund, if negative $(U L<0)$, or a pension liability, if positive $(U L>0)$. The evolution of the reserve fund $F(t)$ in $t \in[0, T]$, with $F(t) \gtreqless 0$, is given by:

$$
F(t)=F(t-1)[1+g(t-1)]+C(t)-B(t)
$$

Where the notional rate $g$ is the rate of return remunerating the reserve fund.

With reference to the financial sustainability of the system, we measure it by the total unfunded liabilities $(T U L)$ over a fixed time horizon $(0, T)$ that we define as the difference between the present value of future benefits and the present value of future contributions discounted at the notional rate $g(t)$, consistently with the rate of return that remunerate the notional account:

$$
T U L(0, T)=\sum_{t=1}^{T} B(t) v_{g}(0, t)-\sum_{t=1}^{T} C(t) v_{g}(0, t)
$$

where $v_{g}(0, t)=\prod_{h=0}^{t-1}[1+g(h)]^{-1}$. Equation 2.35 can be rewritten as the present value of all future unfunded liabilities $U L(t), t=1,2, \ldots, T$ throughout the accumulation phase before retirement:

$$
T U L(0, T)=\sum_{t=1}^{T} U L(t) v_{g}(0, t)
$$

Remark The system's financial sustainability can be measured though the difference between the reserve fund at final and initial time. A proof for this statement is given in the following. From Eq. 2.34, we derive the expression of the reserve fund at final time $T$ :

$$
F(T)=\sum_{t=1}^{T}[C(t)-B(t)] m_{g}(t, T)+F(0) m_{g}(0, T)
$$

where $m_{g}(t, T)=\frac{v_{g}(0, t)}{v_{g}(0, T)}$. Recalling that $U L(t)=B(t)-C(t)$, we obtain that:

$$
F(0)-F(T) v_{g}(0, T)=T U L(0, T)
$$

Following the sustainability $\mathrm{ABM}$, we assume $F(0)=0$ and we do not take into account the return of the reserve fund.

Note that using $T U L$ as a measure of financial sustainability is in line with the financial solvency measure adopted in the U.S. old-age and survivors insurance (OASI) and disability insurance (DI) social security programs. Actually, the U.S. actuarial balance measures the difference between the present value of pension benefits and the present value of contributions, on a 75-year time horizon, taking into account the trust fund assets at initial period and a minimum level of the trust fund assets at final period (Vidal-Meliá 2010). 
It is worth noting that if we only refer to sustainability, a pure NDC system could not guarantee the social adequacy. Therefore, an adequacy measure should be considered in ABMs modeling. As stated by Schokkaert et al. (2018), "an equitable and credible promise should relate future pensions to the future average living standard in society", consequently an adequacy measure could be defined as the ratio between the average pension paid by the system and the average wage earned by the active population. Actually, a NDC system can only achieve the financial sustainability in the unrealistic case of a system in steady state (Valdés-Prieto 2000; Vidal-Meliá 2010), as it is vulnerable to demographic and economic shocks. For example:

- changes in life expectancy produce immediate effects on $D(t)$ and $b_{z}(t)$ (due to the changes in $\ddot{a}(x, t))$, and delayed effects on $r(t)$ because the benefits to the existing pensioners are not usually indexed to life expectancy;

- changes in unemployment rate produce immediate effects on $D(t)$ not automatically adjusted by the system when pension benefits are not directly linked to the unemployment rate (as e.g. in Italy and Sweden);

- otherwise, the system could experience a variation of the benefit ratio that is not compensated by the dependency ratio when the growth rate of wage, $\xi(t)$, and the pension indexation rate, $\lambda(t)$, do not coincide. Also in this case the equilibrium equation is not satisfied.

\section{Automatic balance mechanisms and quasi NDC systems}

This section presents Automatic Balance Mechanisms (ABMs) for NDC systems based on three control variables, the notional rate, benefits indexation and the contribution rate. As previously observed, the NDC system does not always create financial sustainability, that can be achieved through the introduction of ABMs. Vidal-Meliá (2010) define an ABM as "a set of predetermined measures established by law to be applied immediately as required accordingly to the solvency or sustainability indicator...to re-establish the financial equilibrium of PAYG pension systems with the aim of making those systems viable without the repeated intervention of the legislators". The authors observe that the most relevant features of ABMs should be automation, short-term, rationality, transparency and gradualness.

Academic research has produced different proposals on this topic, e.g. D'Addio and Whitehouse (2012) suggested automatic adjustments on benefit levels according to changes in life expectancy, through the revaluation of past earnings with inflation instead of the average growth rate of earnings and pensions indexation; Gannon et al. (2016)) proposed ABMs based on three decision variables, the growth rate of contribution rate, retirement age and indexation of pensions. The mechanisms actually adopted in many developed countries to enforce the sustainability of PAYG pension schemes (DB, point or NDC systems) mainly have been the indexation of pension benefits, or the minimum retirement age, or the minimum years of contributions required for a full benefit to life expectancy (see Vidal-Meliá 2010; Gannon et al. 2015 for a description of ABMs adopted in Sweden, Canada, Germany, Japan, Finland and US). ${ }^{6}$ Among the developed countries with a NDC pension system, Sweden is the only one that has introduced an ABM (reform in May 2001). The Swedish system provides that the notional rate applied to notional capital and the indexation rate of pension

\footnotetext{
6 It should be noticed that some of them are more effective when applied to DB or point systems than to NDC. For example, in a NDC, indexing the retirement age to life expectancy would improve the social adequacy but would not change the financial stability of the system.
} 
benefits (usually equal to the average wage growth) are reduced when the system's solvency indicator falls below one. The solvency indicator is determined as a "balance ratio"between assets (contribution asset plus buffer fund) and pension liability (Settergren 2001). ${ }^{7}$

Even if an ABM could allow a NDC system to become financially sustainable, it may be socially undesirable due to sudden adjustments. Therefore, an automatic mechanism should work gradually so as to prevent jumps in the paths of the ABM reference variables. A critical aspect of automatic adjustments applied to a NDC system is that it could not guarantee adequate pension benefits to pensioners, raising social adequacy issues. Indeed, as observed by Schokkaert et al. (2018), the financial sustainability is not able to keep the system "socially"sustainable. As experienced in some countries, pension reforms aiming to reach the financial sustainability led to inadequate pensions depressing the living standard of pensioners and making the pension system less appealing for young generations.

As we will show later in the case of Italy, ABMs operating on notional rate and pension indexation do not assure adequate pensions. For this reason, we focus on a combination of $\mathrm{ABMs}$ that guarantees financial sustainability by minimizing a cost function measuring the social adequacy of the pension system by the benefit ratio $r(t)$. A possible way of providing adequate pensions, under financial sustainability constraints, is to increase the contribution rate. Such an increase would introduce an aging risk sharing between beneficiaries (pensioners) and contributions payers (actives): actually, it enforces the financial sustainability, not reducing the current pensions, and, at the same time, increases the actives' notional amount, and therefore produces higher and more adequate pensions in the future. Then, in this paper, the contribution rate is one of the ABM decision variables, that can be increased/decreased in order to enforce the adequacy and/or the sustainability of the NDC system. We define this system as "Quasi Notional Defined Contribution"(Quasi-NDC) to show that this variable, typically constant in a NDC system, could change.

The increase of social security contributions could create a negative impact on labour costs and the market side, therefore on the long-term sustainability of the scheme itself. The analysis of such eventual economic consequences is beyond the scope of this paper, but we can observe that some measures can mitigate these potential negative effects:

- In the optimization problem, that defines ABMs, we simultaneously introduce an absolute upper bound and a relative maximum yearly increase for the contribution rate, moderating the effects on the labour market; this kind of automatic balance mechanism with continuous control and progressive effect avoids sudden shocks.

- We can consider the contribution rate obtained by the optimization problem as an implicit rate, necessary for the global equilibrium of the PAYG scheme. However, this cost could be partially paid by social contributions on wages and partially by other tax sources (for instance solidarity contributions on other kinds of incomes).

In light of the above considerations, we propose an $\mathrm{ABM}^{8}$ based on the following adjustments at time $t$ :

\footnotetext{
7 See also Boado-Penas and Vidal-Meliá (2013) for a description of the Swedish ABM.

8 Another possible adjustment mechanism could work on the calculation of pension benefits at retirement. e.g. some countries with DB PAYG systems, such as Portugal or Finland, link the initial pension benefits to life expectancy improvements. Such an adjustment is implicit in a NDC system where the annuity rate is periodically updated to new life tables. What we exclude here are adjustments at the moment of retirement not linked to the life expectancy improvement. Note that the introduction of these adjustments would be politically unacceptable because of the definition of NDC: it could suddenly decrease the notional capital at the moment of retirement, not allowing the pensioner to revise its choices in order to obtain an adequate pension.
} 
$-\gamma(t)$ in the benefits indexation rate:

$$
B(x, t)=B(x-1, t-1) p^{22}(x-1, t-1)[1+\lambda(t-1)] \gamma(t)+B_{z}(x, t)
$$

$-\zeta(t)$ in the notional rate:

$$
M(x, t)=M(x-1, t-1) p^{11}(x-1, t-1)[1+g(t-1)] \zeta(t)+C(x, t)
$$

$-\theta(t)$ in the contribution rate:

$$
C(x, t)=c \cdot S(x, t) \cdot \theta(t)
$$

The design of an ABM can be symmetric or asymmetric. The first occurs when adjusting for both positive and negative deviations from the financial sustainability indicator and the second involves only negative adjustments in pension benefits (lower rate indexation of pensions, lower notional rate) and a higher contribution rate. See Gannon et al. (2016) for a discussion about the implication on the sustainability of PAYG systems of implementing symmetric or asymmetric designs. Disregarding positive adjustments in pensions would penalize social adequacy, while disregarding lower contribution rate would have negative implications in the labour market. Therefore, although asymmetric ABMs are mainly used in practice, we only consider the symmetric case.

The adjustments $\gamma(t)$ and $\zeta(t)$ impact on the amount of total pensions paid by the system, $B(t)$ : the first directly, reducing or increasing the pension indexation (that can even become negative, ${ }^{9}$ ) the second indirectly, reducing or increasing the notional amount that determine the future pensions. Conversely, $\theta(t)$ works on the amount of total contribution, $C(t)$, increasing or decreasing the future values of notional amounts and pensions.

\section{Optimization problem formulation}

This section lays out the design of an ABM that automatically adjusts NDC systems in order to guarantee either social adequacy and financial sustainability. The following subsections describe the optimization problem used to calculate the optimal paths of the decision variables involved, $\gamma(t), \zeta(t)$ and $\theta$, respectively operating on the benefits indexation, notional rate and contribution rate, as described in Sect. 3. In (4.1) we specify the objective function to minimize, in (4.2) the constraints on financial sustainability and liquidity as well as upper and lower bounds and smooth constraints for the decision variables, and in (4.3) the optimization problem.

\subsection{Objective function}

The objective function is a Total Penalty Function, denoted by $T P F(0, T)$, that considers both social adequacy and contribution rate sustainability on the whole period $(0, T)$. The annual adequacy of the pension system is measured by the benefit ratio $r(t)$, setting a minimum level $c_{1}$ that we consider desirable. However, to meet adequacy and sustainability, a pension system must set the contribution rate at an economically acceptable level, to avoid negative repercussions on the labour market. Therefore, we specify a maximum level $c_{2}$ for the contribution rate. Moreover, we introduce in the objective function two penalty factors,

9 As observed by Gannon et al. (2016), Sweden has already applied a negative indexation of pensions to reach the financial sustainability. 
$\psi_{1}$ and $\psi_{2}$, representing the social weights given to the failure in achieving the desirable levels for the benefit ratio and the contribution rate, respectively. The first penalty factor, $\psi_{1}$, is triggered when the benefit ratio is under the fixed level $c_{1}$, while the second one, $\psi_{2}$, when the contribution rate is above the level $c_{2}$. The TPF is then defined as:

$$
T P F(0, T)=\sum_{t=1}^{T}\left\{\psi_{1}\left[c_{1}-r(t)\right]^{+}+\psi_{2}\left[c(t)-c_{2}\right]^{+}\right\}
$$

where $c(t)$ is the contribution rate that makes the system financially sustainable with the help of the ABMs.

\subsection{Constraints}

Financial sustainability constraint We introduce a null constraint at the total unfunded liabilities over the fixed time horizon $(0, T)$. However, it is well-known that in practice it is not possible to precisely verify this equality (Gannon et al. 2016), therefore we include two constraints in the optimization problem, so that the $T U L(0, T)$ is within a narrow range. Specifically, we require that the absolute value of the ratio between the $T U L(0, T)$ and the contributions in the first year $C(1)$ is not higher than a small level $\varepsilon$.

$$
-\varepsilon \leq \frac{T U L(0, T)}{C(1)} \leq \varepsilon
$$

TUL $(0, T)$ is divided by $C(1)$ in order to relate the total unfunded liabilities to the size of the NDC system. According to Eq. 2.38, this constraint is equivalent to setting $F(T)=0$, when $F(0)=0$.

Liquidity constraint The second constraint refers to the acceptance by the NDC system of an annual temporary deficit. We assume a possible temporary deficit on year $t$, but it must not exceed a maximum level $u$ respect to the total contribution. Therefore, the annual unfunded liabilities in respect to the total contribution should be less than $u$ :

$$
\frac{U L(t)}{C(t)} \leq u
$$

Lower and upper bounds of the decision variables In order to avoid strong adjustments on pensions, notional accounts and contributions that would be socio-political unacceptable, we introduce lower and upper bounds, $G_{1}, G_{2} ; Z_{1}, Z_{2}$ and $T_{1}, T_{2}$, on the decision variables $\gamma$, $\zeta$ and $\theta$, respectively. Hence, the decision variables must be in the following ranges:

$$
G_{1} \leq \gamma(t) \leq G_{2}, \quad Z_{1} \leq \zeta(t) \leq Z_{2}, \quad T_{1} \leq \theta(t) \leq T_{2}
$$

Smooth constraints for the decision variables The last set of constraints concerns the changes of $\gamma, \zeta$ and $\theta$ that should be in a reasonable range in order to prevent jumps in the paths of the pensions, notional accounts and contributions which would be socially undesirable. Smooth constraints are set as:

$$
g_{1} \leq \frac{\gamma(t)}{\gamma(t-1)} \leq g_{2}, \quad z_{1} \leq \frac{\zeta(t)}{\zeta(t-1)} \leq z_{2}, \quad t_{1} \leq \frac{\theta(t)}{\theta(t-1)} \leq t_{2}
$$

As explained in the introduction, our formulation of the optimization problem shows some similarities with the problem introduced by Gannon et al. (2016): the use of contribution rate and indexation of pensions as decision variables, the presence of lower and upper bounds of the decision variables and smooth constraints. However, our objective function (the TPF) 
considers both social adequacy and contribution rate sustainability, differing from the one proposed in Gannon et al. (2016) involving the pension system's sustainability via the actuarial balance. The objective function proposed by Gannon et al. (2016) can be found, in our framework, in the Total Unfunded Liabilities that are included in the optimization problem as a constraint.

\subsection{Optimization problem}

The optimization problem for a NDC pension scheme is as follows:

$$
\begin{aligned}
& \min _{\gamma(t), \zeta(t), \theta(t)} T P F(0, T) \\
& \text { subject to } \\
& -\varepsilon \leq \frac{T U L(0, T)}{C(1)} \leq \varepsilon \\
& \frac{U L(t)}{C(t)} \leq u \\
& G_{1} \leq \gamma(t) \leq G_{2} \\
& Z_{1} \leq \zeta(t) \leq Z_{2} \\
& T_{1} \leq \theta(t) \leq T_{2} \\
& g_{1} \leq \frac{\gamma(t)}{\gamma(t-1)} \leq g_{2} \\
& z_{1} \leq \frac{\zeta(t)}{\zeta(t-1)} \leq z_{2} \\
& t_{1} \leq \frac{\theta(t)}{\theta(t-1)} \leq t_{2}
\end{aligned}
$$

It is a nonlinear problem that can be solved by some efficient algorithms with a moderate computational cost. In the following we provide some details on the algorithm used to solve the optimization problem, that has been developed in R. The optimal solutions have been estimated using the Constrained Optimization BY Linear Approximations (COBYLA) algorithm in the nloptr package (Ypma 2018), which is an $R$ interface to NLopt, a library for nonlinear optimization (Johnson 2010). COBYLA is an algorithm for derivative-free optimization belonging to the category of non-gradient based local search methods and supporting non-linear equality and inequality constraints (Powell 1994). It is suitable for solving our optimization problem where the derivative of the objective function is not known. The optimal paths we find are local and the solution to the problem is not theoretical.

\section{Numerical application}

In the numerical application we apply to the Italian NDC pension system the ABMs obtained by solving the optimization problem defined in Sect. 4. The NDC system has been progressively implemented in Italy since 1995 for new entrants in the labour market, both employees and self-employed. In 2011 the system was extended to the overall population. ${ }^{10}$

10 A DB system applies only to some residual categories of workers such as freelance professionals. 
We created a simplified population using the demographic and economic structure of the National Employees' Pension Fund members. The population's features are shown in Sect. 5.1.

The numerical application is divided into three parts: first, we verified the ability of the proposed ABM to restore the pension system's financial sustainability and social adequacy. Actually, despite the introduction of the NDC, the system is far from the equilibrium and could lead to social adequacy problems. In this first analysis, we adopted the hypotheses of demographic and economic evolution that was used by the Ministry of Finance in the long-term projections of Italian pension expenditure (Ragioneria Generale dello Stato 2018).

In the second, we performed a sensitivity analysis to verify the effects of different demographic and economic conditions on the ABMs. Specifically, we developed two alternative scenarios: the first was characterized by lower employment level and labour productivity than the base scenario, the second with the final employment level and labour productivity equal to the base scenario but with lower initial growth and higher final growth.

In the third part, we developed a sensitivity analysis to test how the optimal paths of decision variables are influenced by the choice of different penalty factors in the objective function, T PF, showing the impact of different political choices on the ABMs.

It is well known that actuarial reports to evaluate the financial sustainability of a pension system have to consider very long time horizons: as pointed out by Boado-Penas and VidalMeliá (2013),), “the minimum time horizon should be the system's turnover duration, the normal value of which varies between 30 and 35 years, although actuarial reports often contemplate a minimum horizon of 75 years". In the US the actuarial balance of the social security programs adopts a 75 year time horizon, the same in Canada for the actuarial valuation of the Canada Pension Plan realized by the Office of the Chief Actuary; in Japan, the Actuarial Affairs Division of the Ministry of Health compiles a 95 year time actuarial balance (Gannon et al. 2016); finally, in Italy, the last long-term projections of Italian pension expenditure that were made by the Ministry of Finance refer to the period 2018-2070 (Ragioneria Generale dello Stato 2018).

In the numerical application we use 75 year time horizon, compliant with the minimum value often considered in actuarial reports. This time horizon implies that at the end of the projection the cohort of baby-boomers (initially included in the actives' population) has been completely exhausted, so that the final demographic structure is scarcely influenced by this demographic phenomenon. ${ }^{11}$

\subsection{Data and assumptions}

The initial population considered in the case study has the following features:

- Initial active population: $N^{1}(0)=1000$, all males. The initial age distribution of actives is taken from the observed distribution of the Italian National Institute of Social Security (INPS) pension scheme for employees in 2015. The average age is 42.3.

- The initial wage distribution of the active population by age, $s(x, 0)$, is taken from the employees' observed wage distribution in 2015 (source: INPS). The average wage of the initial active population is $s(0)=29,617$ (Euro).

11 More precisely, the effect of a demographic shock is not completely absorbed at the time of death of the last member of the baby boomers' cohort but requires the achievement of the steady state to be exhausted. 


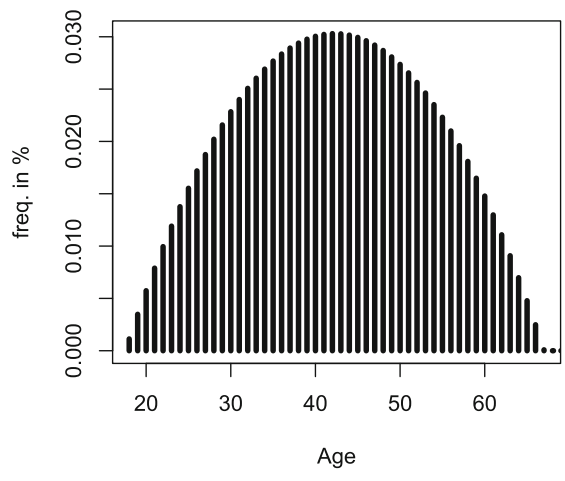

(a) Actives

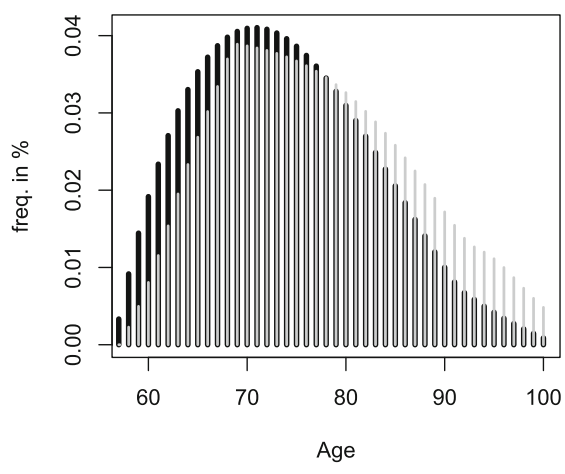

(b) Pensioners

Fig. 2 Age distribution of actives and pensioners in $t=0$ (black bins) and $t=T$ (grey bins)

- The initial dependency ratio is set to be representative of the dependency ratio of the INPS pension scheme for employees ${ }^{12}: D(0)=43.6 \%$ in 2015 . Consequently, the initial pensioners' population is $N^{2}(0)=436$. The initial age distribution of pensioners is taken from the observed distribution of INPS pension scheme for pensioners in 2015, which average age is 73.9 .

- The initial distribution of pension benefits by age is taken from the observed distribution of INPS pension scheme for pensioners in 2015, which average amount is 21,175 (Euro).

The age distribution of actives and pensioners at initial and final time is shown in Fig. 2.

We make the following assumptions on the evolution of actives and pensioners:

- The age distribution of new entrants in the active state is built in accordance with the observed age distribution of the actives with past service duration lower than 2 years in 2015. It is assumed to be constant over time $\left(d_{z}(x, t)=d_{z}(x)\right)$ (see Fig. 3).

- Transition probabilities at initial time, $p^{12}(x, 0)$, are built from the experience of the INPS pension scheme for employees in $2015 .^{13}$ The use of a time varying probability distribution allows us to represent the progressive increase of the minimum retirement age, and the future actives expected propensity to remain longer at work. The retirement propensity decreases over time and halves in $\mathrm{T}=75$ (see Fig. 4 left panel).

- Transition probabilities, $p^{13}(x, t)$, are assumed to be 0 for all ages and time. This implies that we disregard mortality among actives. ${ }^{14}$

- Transition probabilities at initial time, $p^{23}(x, 0)$, are obtained from the data provided by INPS on the mortality experience of pensioners, where we set the maximum attainable age at 100 . These probabilities decreases over time and halves in $\mathrm{T}=75$ consistent with the average reduction factor calculated from the official mortality projections 2015-2065 provided by the Italian National Institute of Statistics (ISTAT)(see Fig. 4 right panel).

Consistently with the Italian pension legislation, we set the notional rate, $g(t)$, equal to the GDP growth rate and pension indexation, $\lambda(t)$, equal to the inflation rate.

\footnotetext{
12 In determining the dependency ratio, we only consider the old-age pensioners as in the case study we disregard invalidity and survivors benefit.

13 Instead of adopting the simple assumption that actives retired at the minimum retirement age, we adopt a probability distribution from observed data in order to work with a more realistic case.

14 As previously described, in Italy the distribution of inheritance gains is not considered, consequently these probabilities do not affect the evolution of the accumulated notional capital (see Eq. 2.23).
} 
Fig. 3 Age distribution of new entrants in the active state

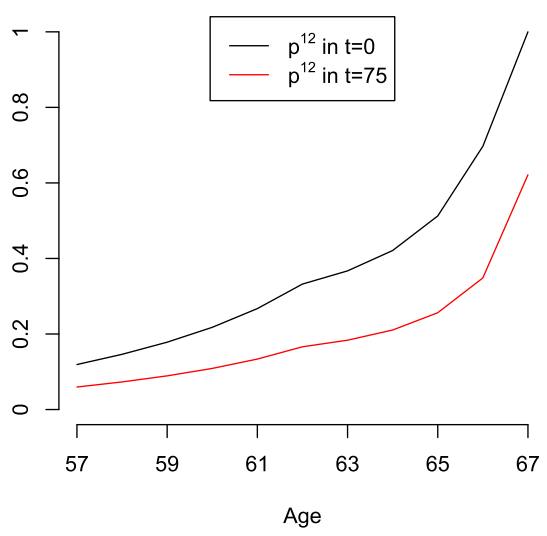

(a) $p^{12}(x, t)$
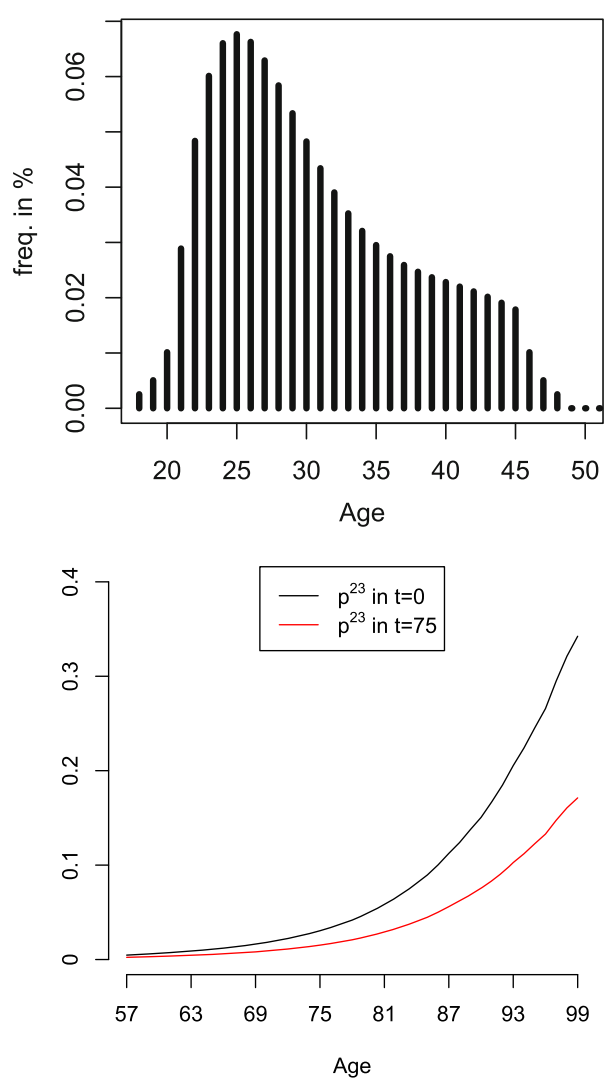

(b) $p^{23}(x, t)$

Fig. 4 Left panel: transition probabilities, $p^{12}(x, t)$ in $t=0$ and $t=75$. Values for ages from 18 to 56 are always set equal to 0 , while values for ages from 68 to 100 are always set equal to 1. Right panel: transition probabilities, $p^{23}(x, t)$ in $t=0$ and $t=75$

In the actuarial valuation we adopt a constant discount rate $j(t)$ equal to the long run trend of notional GDP growth rate.

The economic assumptions are coherent with the standard ones of the Ministry of Finance for the projection of the national pension expenditure (Ragioneria Generale dello Stato 2018). Therefore, we assume that the GDP growth rate is equal to the sum of the growth rate of the active population, labour productivity and inflation rate. The growth rate of the individual wage, $\xi(t)$ is equal to the labour productivity coherently with the model described in Sect. 2.

In the base case scenario, we make the following assumption on the economic evolution:

- The growth rate of the active population $\rho(t)=0 \forall t .^{15}$

- The inflation rate is 0 for each year and hence $\lambda(t)=0 \forall t .^{16}$

15 This choice is consistent with the national scenario-based medium to long-term forecasts made by the Ministry of Finance, which assume a final active population substantially equal to initial one.

16 Numerical tests we carried out with non-zero inflation assumptions show a negligible impact of inflation on the adjustment factors obtained by the ABMs, therefore we decided to neglect inflation in the numerical application. 


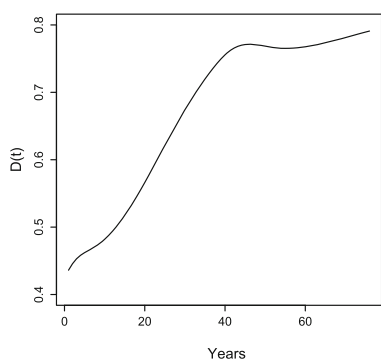

(a) Dependency ratio

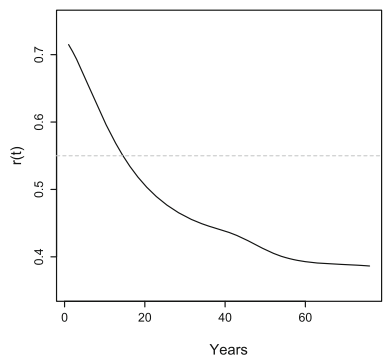

(b) Benefit ratio

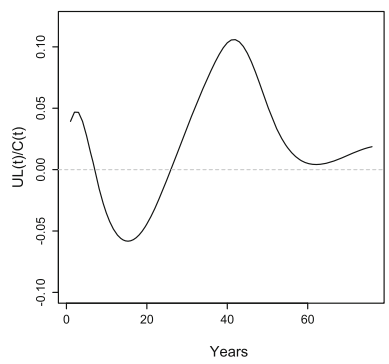

(c) Unfunded liabilities ratio

Fig. 5 Pension system evolution under the base scenario without ABMs

- The labour productivity is set at $1.5 \%$ and hence $\xi(t)=1.5 \% \quad \forall t .^{17}$

Therefore, $g(t)=1.5 \% \forall t$ and $j(t)=1.5 \% \forall t$. Finally, the contribution rate $c(t)$ is set to $0.3 .{ }^{18}$ The dynamics of dependency ratio, benefit ratio and UL ratio in the base scenario, without any automatic adjustment, are reported in Fig. 5. The dependency ratio of the pension system increases from $43.6 \%$ to $79.1 \%$ in 75 years (due to the increase of life expectancy), the benefit ratio decreases from $71.5 \%$ to $38.6 \%$ (due to the annuity rate increase) and the total unfunded liabilities, $T U L(0,75)$, is $14.4 \mathrm{mln}$, equal to the $162.5 \%$ of the first-year contributions. Therefore, the financial sustainability is not reached by the pension system. Moreover, Fig. 5 (panel b) clearly shows a severe decrease of the benefit ratio $(r(t)$ decreases by $32.9 \%$ ), illustrating the social adequacy issue in a NDC system without adjustments. In this situation, any government action aimed at enforcing the financial sustainability, maintaining the system's adequacy unchanged, would be socially unfair.

In order to calculate the $T P F$, we have to set the penalty factors, the target levels for the benefit ratio, $c_{1}$, and the contribution rate, $c_{2}$. We set $c_{1}$ as a proportion of the initial benefit ratio $r(0)$. Since $r(0)$ is very high (71.5\%), ${ }^{19}$ a $25 \%$ reduction can be considered a reasonable limit that can be socially acceptable. Therefore, $c_{1}=0.75 \cdot r(0)=0.536$.

The other bound, $c_{2}$, is set as a proportion of the initial contribution rate. The $c(1)$ value is currently very high and a $5 \%$ increment can be reasonable in order to limit its impact on the labour market. Therefore, $c_{2}=1.05 \cdot c(1)=0.315$.

We fix the penalty factors at the same level $\left(\psi_{1}=\psi_{2}=0.5\right)$ to give the same importance to the benefit ratio adequacy and the contribution rate acceptability. The TPF in the base scenario without automatic adjustments is equal to 3.20 .

In the financial sustainability constraint, we set $\varepsilon=0.1 \%$ which means that $T U L(0,75)$ cannot exceed $0.1 \%$ (or fall short of $-0.1 \%$ ) of the first year contributions $(C(1)=8.9 \mathrm{mln}$ ). We consider $0.1 \% \cdot C(1)$ a negligible value compared to the economic dimension of the problem: in the base scenario without $\mathrm{ABMs} T U L(0,75)$ is $14.4 \mathrm{mln}$, while the corresponding value obtained with ABMs is in the range $(-8.885,8.885)$.

\footnotetext{
17 This hypothesis is consistent with the long-term labour productivity value adopted by the Ministry of Finance in the national scenario-based medium to long-term forecasts.

18 The contribution rate, $c(t)$, is set according to that of the Italian pension system: currently equal to $33 \%$, including invalidity benefits, survivors' benefits and withdrawals. These latter benefits are not considered in our case study.

19 The initial value obtained in our case study is very close to the estimated value provided by the Ministry of Finance in 2020, $71 \%$ (see Ragioneria Generale dello Stato 2018). Note that this value is much higher than the OECD countries average value, 52.9\% (see OECD 2017) therefore we consider reasonable to reduce it.
} 
In the liquidity constraint, we set $u=5 \%$ considering that the initial value of the ratio between the annual unfunded liabilities and the total contribution is already close to $4 \%$ in $t=0$ and that, in the absence of ABMs, it would exceed $10 \%$ after 40 years. Halving the maximum value that can be reached by the liquidity ratio, seems to be a desirable and reasonable result.

In order to avoid strong adjustments on pensions, notional accounts and contributions, lower and upper bounds on the decision variables were introduced in the optimization problem. The lower bounds $G_{1}, Z_{1}$ and $T_{1}$ on the decision variables $\gamma(t), \zeta(t)$ and $\theta(t)$ are given respectively by $0.95,0.95$ and 0.85 . The upper bounds $G_{2}, Z_{2}$ and $T_{2}$ are $1.05,1.05$ and 1.15 , respectively. To prevent jumps in the optimal paths of the decision variables, smooth constraints were introduced. We set $g_{1}, z_{1}$ and $t_{1}$ respectively to $0.99,0.99$ and 0.95 , and $g_{2}$, $z_{2}$ and $t_{2}$ to $1.01,1.01$ and 1.05 .

We believe it is unrealistic to assume that governments change pension policy too frequently, therefore, we propose that each ABM should change every $k$ years. Therefore:

$$
\gamma(t+1)=\gamma(t) ; \zeta(t+1)=\zeta(t) ; \theta(t+1)=\theta(t) \text { for } t \neq k, 2 k, \ldots
$$

In the following, we set $k=5$. $^{20}$

\subsection{Results under the base scenario}

In this section the results of the optimization model are reported, first working on single ABMs, second on double and triple ABMs. We show the $T P F$ values in the base scenario under different combinations of ABMs in the "Appendix B" (Table 2). The evolution of benefit ratio, UL ratio, benefits indexation, notional rate and contribution rate is reported in Fig. 6 for single ABMs, in Fig. 7 for double ABMs and in Fig. 8 for a triple ABM.

In the base scenario, in the case of single ABMs, we obtain a low reduction of the penalty function only when the adjustment factor $\theta$ is considered. In the other two cases $(\gamma$ and $\zeta$ ) the penalty function gets worse, as a consequence of the NDC pension scheme initially being strongly unbalanced. The optimal paths $\left(\gamma^{*}, \zeta^{*}\right)$ aim to set $T U L(0,75)$ to zero by respectively reducing pension benefits and notional capital, lowering the benefit ratio and hence increasing TPF. As can be seen from Fig. 6 (panel b), single ABMs always operate to achieve financial sustainability by producing a surplus in the first years and a deficit (within $5 \%$ of the liquidity constraint) in the last years. Referring to Fig. 6 (panel a), we observe that only the $\theta$-based ABM provides a benefit ratio value stably over the non-optimized one. The optimal path $\gamma^{*}$ reduces the benefits indexation that is almost always lower than the non-optimized one (Fig. 6, panel c). Similarly, $\zeta$ produces an optimized notional rate that is lower than the initial one (Fig. 6, panel d). The $\theta$-based ABM involves a contribution rate increase over the desirable level $c_{2}$ (Fig. 6, panel e), which guarantees both financial sustainability and a slightly higher value of $r(t)$ than without ABMs.

In case of double ABMs (see Table 2 in the "Appendix B"), the results indicate a good $T P F$ reduction achieved by combining $\theta$ with the other decision variables. While, the TPF with the double $\left(\gamma^{*}, \zeta^{*}\right)$ ABM is very close to those calculated with $\gamma^{*}$-based ABM. In other words, when an adjustment on the benefits indexation rate $(\gamma)$ is already present in the system, adding the adjustment on the accumulated notional capital $(\zeta)$ is substantially useless to achieving the objective. The optimal path $\left(\gamma^{*}, \zeta^{*}\right)$ is less effective because both these decision variables work at reducing the amount of pensions in order to achieve financial sustainability, disregarding social adequacy (see the red line in Fig. 7, panel a).

20 According to the duration of the Italian legislature. 


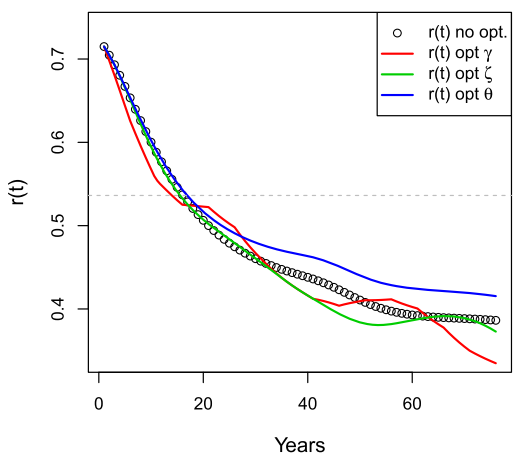

(a) Benefit ratio

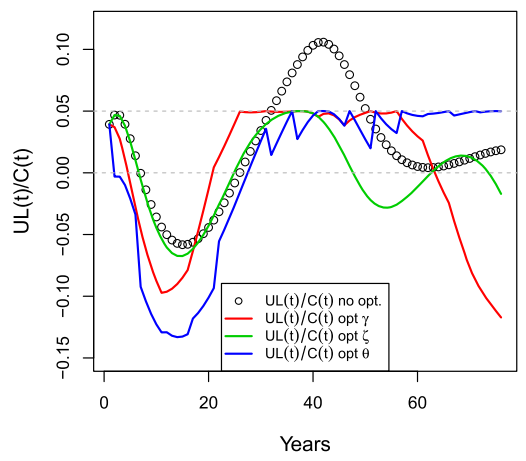

(b) Unfunded liabilities ratio

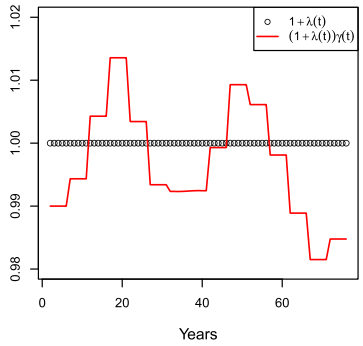

(c) Benefits indexation

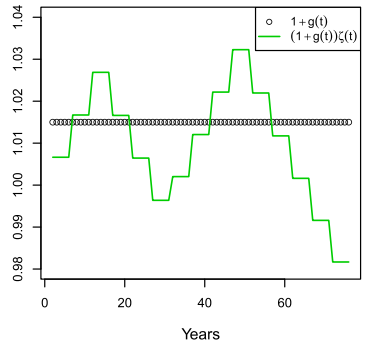

(d) Notional rate

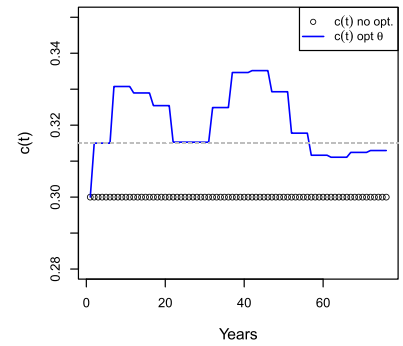

(e) Contribution rate

Fig. 6 Pension system evolution under the base scenario with single ABMs

The double ABMs including $\theta$ lead to contribution rate values above the desirable threshold $c_{2}$, reaching the upper bound $T_{2}=0.345$ (Fig. 7, panel e). From Fig. 7 (panel c) it can be noticed that the benefits indexation under the double ABM based on $\gamma$ and $\theta$ is higher than the indexation obtained with the double $\mathrm{ABM}$ based on $\gamma$ and $\zeta$ : the increase in contribution rate produced by $\theta$ allows to balance the system $(T U L(0,75)$ near to zero) without a strong reduction in the benefits indexation. Note that both these variables produce a higher benefit ratio. Similar considerations could apply to the notional rate that is higher for the double ABM based on $\zeta$ and $\theta$ than for the double ABM based on $\gamma$ and $\zeta$ (Fig. 7, panel d).

When we jointly consider three decision variables, we obtain slightly better $T P F$ results than those achieved by the double ABMs based on $\theta$. The same considerations apply to the evolution of the benefit ratio, unfunded liability ratio, benefits indexations, notional rate and contribution rate.

\subsection{Sensitivity to economic scenario}

In this section we show the results of the optimization procedure under different economic scenarios in order to measure the sensitivity of the optimal ABMs to different assumptions on economic growth. We consider two alternative scenarios in respect to the base one:

- Scenario 2 is characterized by lower employment level and labour productivity than the base one. We set the growth rate of the active population, $\rho(t)$, equal to $-0.5 \% \forall t$. The labour productivity, and hence the growth rate of the individual wage, $\xi(t)$, is set at 


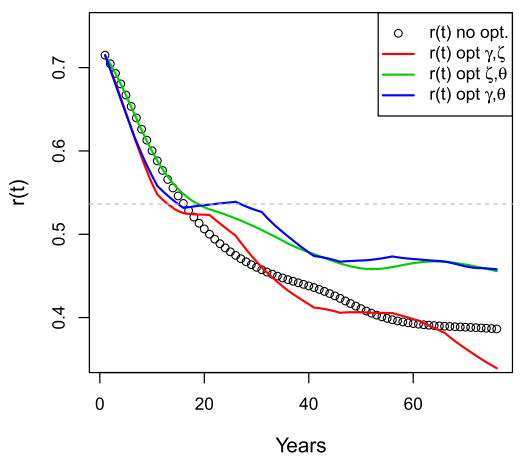

(a) Benefit ratio

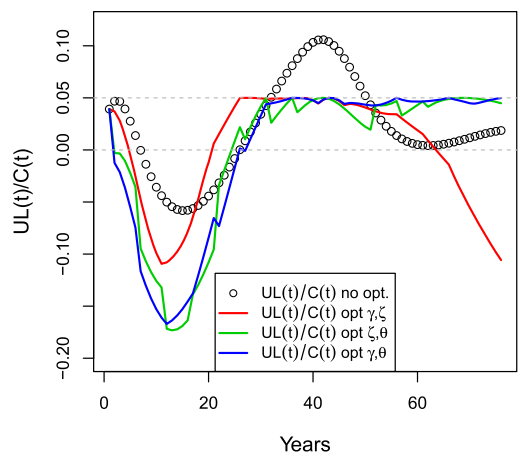

(b) Unfunded liabilities ratio

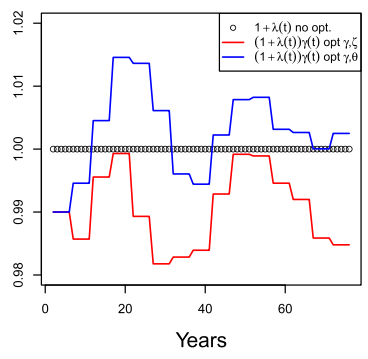

(c) Benefits indexation

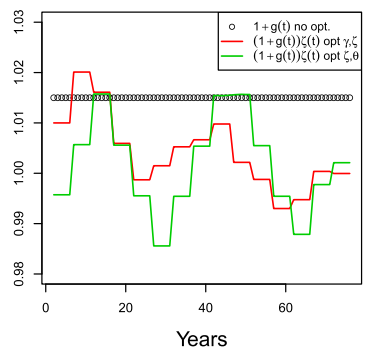

(d) Notional rate

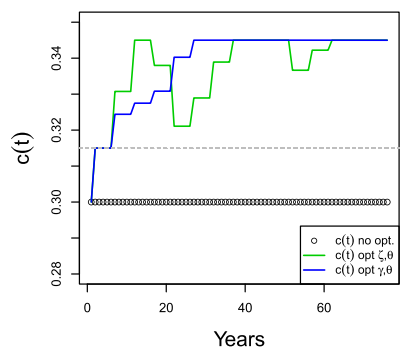

(e) Contribution rate

Fig. 7 Pension system evolution under the base scenario with double ABMs

$1 \% \forall t$. Therefore, $g(t)=0.5 \% \forall t$ and $j(t)=0.5 \% \forall t .{ }^{21}$ The inflation rate is set to 0 for each year (as in the base scenario) and hence $\lambda(t)=0 \forall t$.

- Scenario 3 is characterized by first lower and then higher values of the growth rate of active population and labour productivity. We set $\rho(t)$ equal to $-0.5 \%$ for the first 37 years and then equal to $0.5 \%$ for the last 38 years. The labour productivity and hence $\xi(t)$ is equal to $1 \%$ for the first 37 years and then equal to $2 \%$ for the last 38 years. Therefore, $g(t)$ is equal to $0.5 \%$ for the first 37 years and equal to $2.5 \%$ for the last 38 years. Finally, $j(t)=1.5 \% \forall t$. The inflation rate is set to 0 for each year (as in the base scenario) and hence $\lambda(t)=0 \forall t$.

Scenario 2 was built in order to represent a situation of low economic growth with an employment level reduction. Scenario 3 instead was built to obtain, at the end of the 75-year time horizon, an economic growth and an employment level similar to the base scenario, but considering two successive economic cycles: a first cycle of low economic growth and a second cycle of high economic growth.

In order to better appreciate the differences between the economic scenarios, in Fig. 9 we show the evolution of the dependency ratio, benefit ratio and UL ratio for the three scenarios without ABMs.

21 The value of $j(t)$ is set equal to the average of the GDP growth rate over time; in the case of the base scenario, where $j(t)=1.5 \%$, the annuity rate would be lower and the pension benefits higher, therefore the pension system would experience greater financial unsustainability. In other words, using the average of the GDP growth rate as discount rate works as an automatic adjustment mechanism in times of economic crisis. 


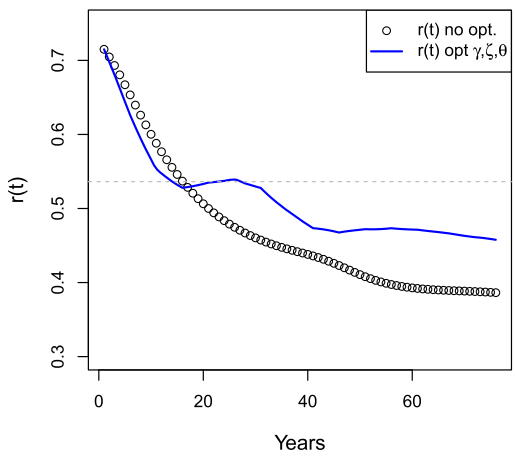

(a) Benefit ratio

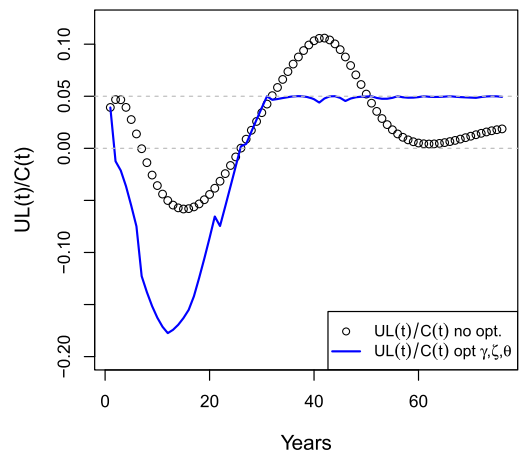

(b) Unfunded liabilities ratio

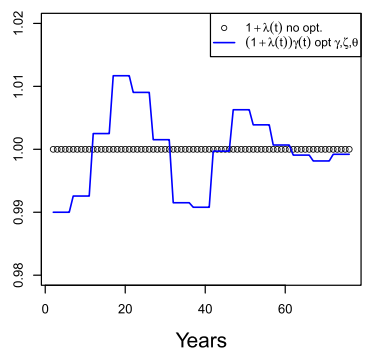

(c) Benefits indexation

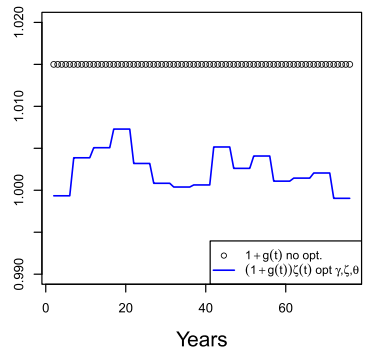

(d) Notional rate

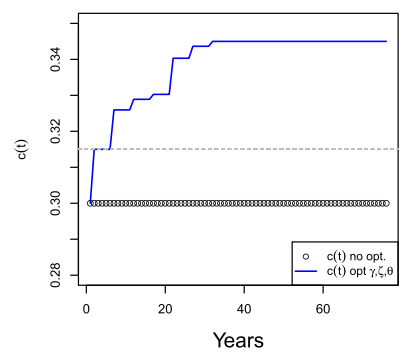

(e) Contribution rate

Fig. 8 Pension system evolution under the base scenario with triple ABM

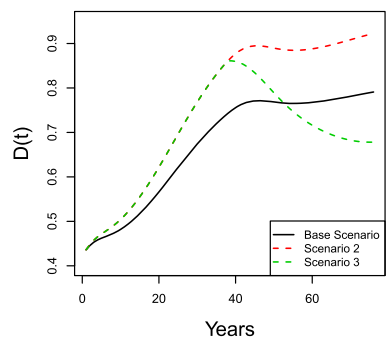

(a) Dependency ratio

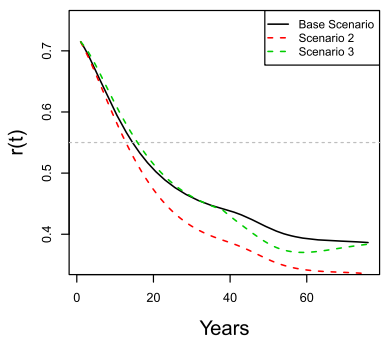

(b) Benefit ratio

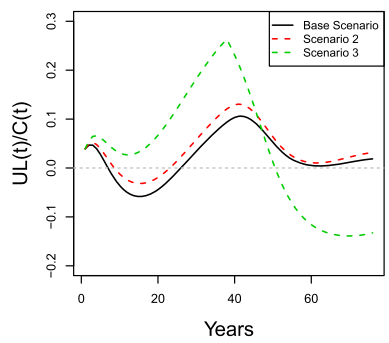

(c) Unfunded liabilities ratio

Fig. 9 Pension system evolution under the three economic scenario without ABMs

In scenario 2, the dependency ratio $D(t)$ increases more than in the base scenario, while in scenario 3, after an initial growth equal to that of scenario 2 (first 37 years), D(t) decreases falling below the base scenario level. With regard to social adequacy, scenario 2 has lower $r(t)$ values than the other scenarios, while in scenario 3 the $r(t)$ performance is similar the base scenario one.

In scenario 2, the unfunded liability $U L(t)$ for each $t$ is greater than the value obtained from the base scenario and $T U L(0,75)$ amounts to $26.6 \mathrm{mln}(299.3 \%$ of the contributions in the first year). In scenario $3, U L(t)$ is greater than the value in both base scenario and scenario 2 for the first 45 years, while it is lower in the remaining years, where the pension system obtains a surplus. The surplus amount is not sufficient to offset the initial liabilities as detected by $T U L(0,75)$ that amounts to $26.1 \mathrm{mln}(294.2 \%$ of the contributions in the first year). 


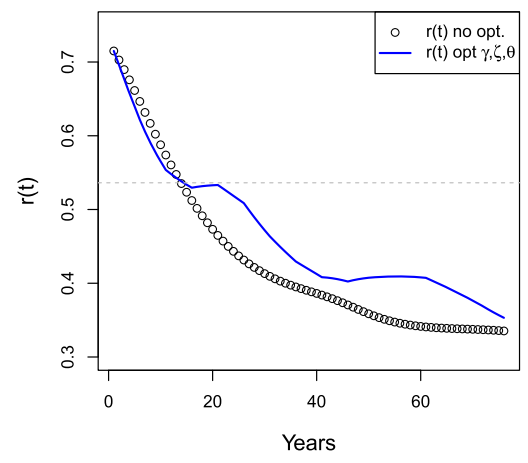

(a) Benefit ratio

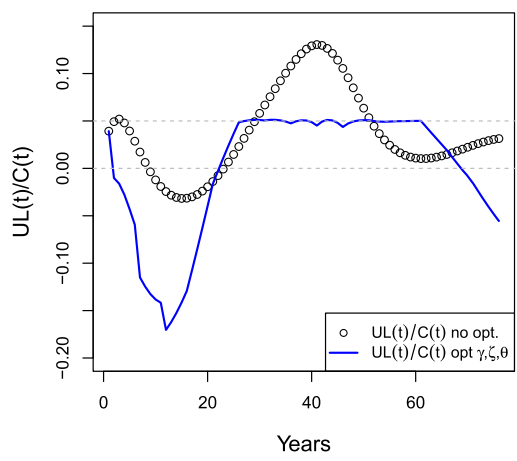

(b) Unfunded liabilities ratio

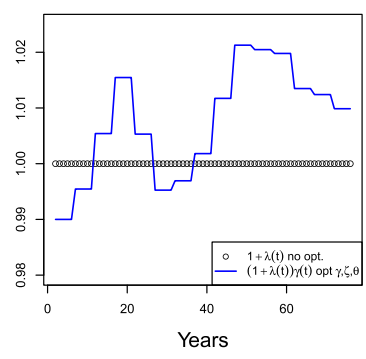

(c) Benefits indexation

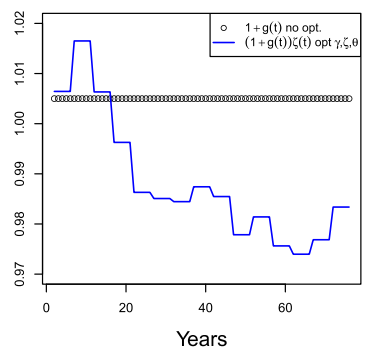

(d) Notional rate

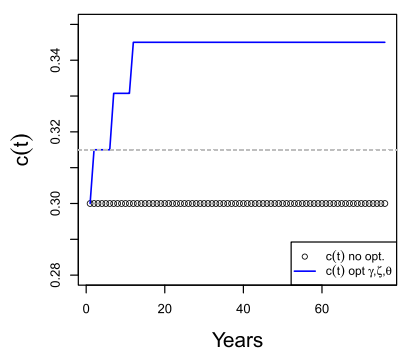

(e) Contribution rate

Fig. 10 Pension system evolution with triple ABM-Scenario 2

The $T P F$ values are reported in the "Appendix B" (Table 3 ) for the three scenarios under different ABMs. The results show that the $T P F$ in scenario 2 and 3 is larger than in the base case, both in the absence and presence of AMBs. It is also noted that, similarly to the base scenario:

- a single ABM is not effective when the decision variables $\gamma$ and $\zeta$ are concerned;

- the double ABMs are more effective when $\theta$ is combined with $\gamma$ or $\zeta$;

- a triple ABM does not strongly improve the TPF respect to double ABMs based on $\gamma$ and $\theta$;

- the decision variable $\zeta$ is the least effective. Adding the decision variable $\zeta$ is only useful in minimizing the objective function, when the economic scenario is not monotone.

The dynamics of benefit ratio, UL ratio and contribution rate when the triple ABM is taken into account are reported in Fig. 10 for scenario 2 and in Fig. 11 for scenario 3.

From Fig. 10, we observe that the triple ABM allows to improve the social adequacy of the system, even if the benefit ratio is far from the desirable level (panel a); moreover, the decision variables optimal paths allow to reduce the $T U L(0,75)$ almost to zero. From panel $\mathrm{c}$, we note that the optimal path of $\gamma^{*}$ produces a benefits indexation often higher than the one without ABM, while from panel d the optimal path of $\zeta^{*}$ generates a notional rate often smaller than the one without ABM. Finally the optimal path of $\theta^{*}$ requires an increase in the contribution rate beyond the desirable level (panel e).

From Fig. 11, we observe that the triple ABM does not improve the social adequacy of the system for the first 40 years but increases the benefit ratio for the last 35 years, reaching 


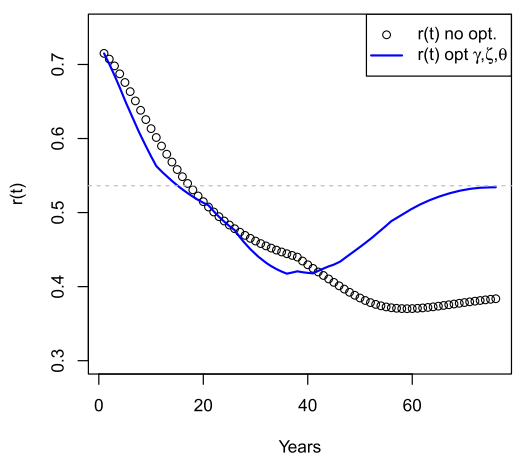

(a) Benefit ratio

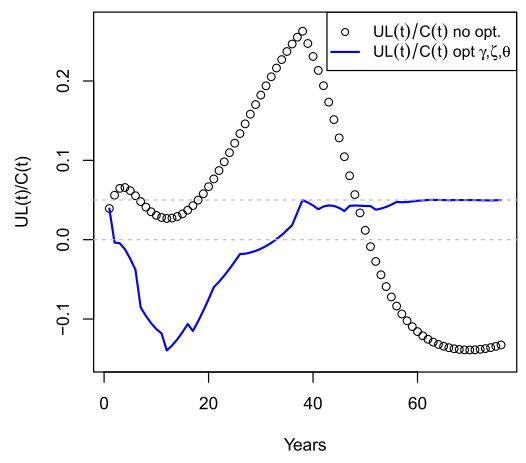

(b) Unfunded liabilities ratio

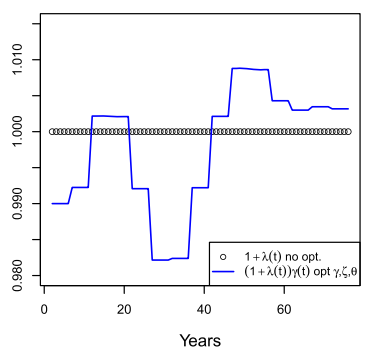

(c) Benefits indexation

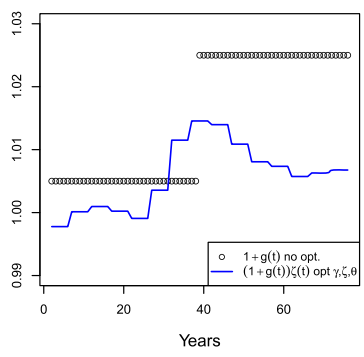

(d) Notional rate

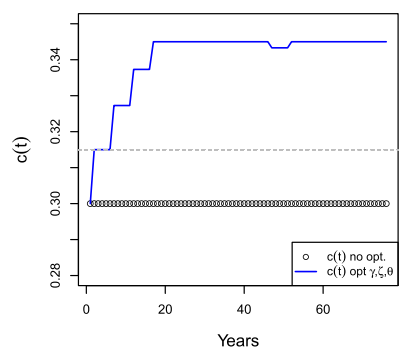

(e) Contribution rate

Fig. 11 Pension system evolution with triple ABM-Scenario 3

the desirable level at the end of the time horizon (panel a). Note also that, in the absence of ABMs, the NDC system would experience a liquidity issue with a value of $\frac{U L(t)}{C(t)}$ higher than $25 \%$ (panel b). Also in the third scenario, the ABMs allow to reduce the $T U L(0,75)$ approximately to zero. The optimal path of $\gamma^{*}$ produces a reduction on benefits indexation for the first 40 years (panel c) and the optimal path of $\zeta^{*}$ a reduction on the notional rate in the last 35 years, when the productivity is rising (panel d). At the same time the optimal path of $\theta^{*}$ requires an increase in the contribution rate up to the fixed upper bound (panel e).

\subsection{Sensitivity to penalty factors}

In this section we show the results of the optimization procedure under different levels of the penalty factors in $T P F$, assuming the economic evolution of the base scenario. The first penalty factor $\psi_{1}$ is triggered when the benefit ratio is below the desirable level $c_{1}$, representing the penalty for the social adequacy failure, while the second one, $\psi_{2}$, when the contribution rate is above the desirable level $c_{2}$ penalizing an excessive level of contribution rate which could have negative effects on the labour market. Changing the penalty factors level allows us to consider different social and economic objectives in the optimization problem. Specifically, we consider a scenario where $T P F$ only involves the adequacy target (scenario A, where $\psi_{1}=1$ and $\psi_{2}=0$ ) and another scenario where $T P F$ considers the contribution rate sustainability and disregards the adequacy (scenario B, where $\psi_{1}=0$ and $\psi_{2}=1$ ). 


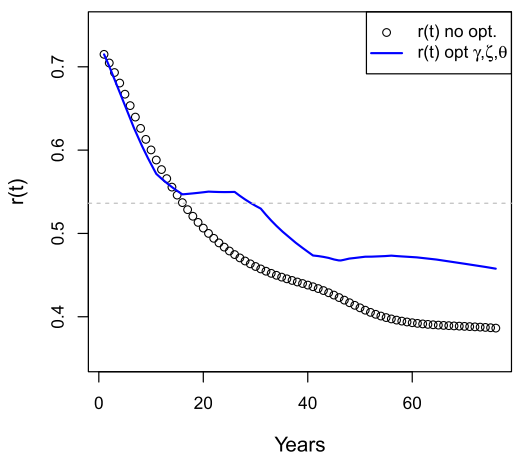

(a) Benefit ratio

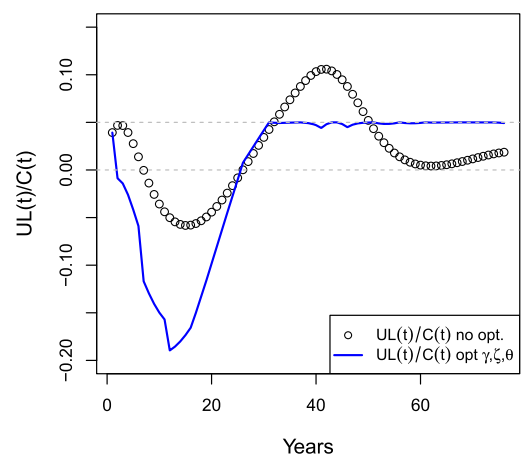

(b) Unfunded liabilities ratio

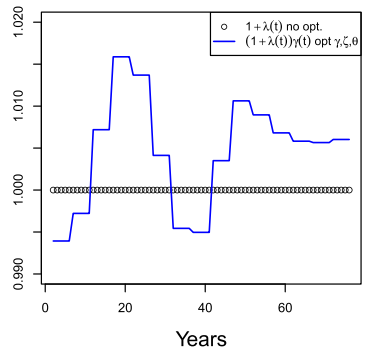

(c) Benefits indexation

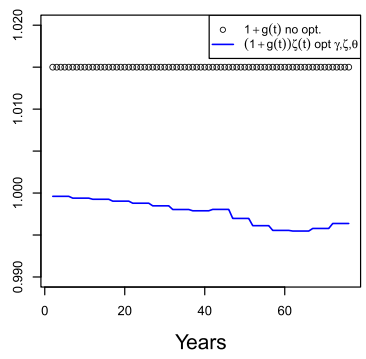

(d) Notional rate

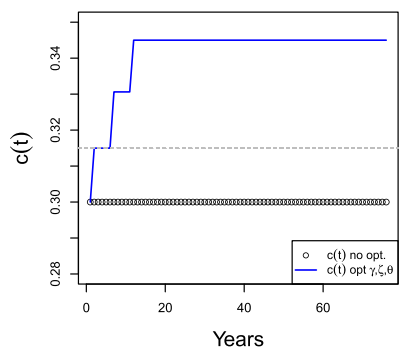

(e) Contribution rate

Fig. 12 Pension system evolution under the scenario A $\left(\psi_{1}=1, \psi_{2}=0\right)$ with triple ABM

As shown in the following, results for scenario B are trivial, therefore we introduce a third scenario in which the penalty factor for adequacy is smaller than the one for contribution rate sustainability, but different from zero (scenario C, where $\psi_{1}=0.25$ and $\psi_{2}=0.75$ ). Table 4 , reported in the "Appendix B", illustrates the $T P F$ values for 3 ABMs according to the base, A, $\mathrm{B}$ and $\mathrm{C}$ scenarios. In scenario $\mathrm{A}$ only social adequacy is considered. In case of single ABMs, $\theta$ is more effective in respect to $\gamma$ and $\zeta$. For the double ABMs, the combinations including $\theta$ are more effective in reducing $T P F$ than the other combinations. In the case of triple ABMs the $T P F$ improvements is insignificant with respect to the double ABM based on $\zeta$ and $\theta$.

Scenario B only considers the contribution rate sustainability and by definition $T P F$ is null in absence of ABMs. When we introduce ABMs to guarantee the financial sustainability, $\gamma$ and $\zeta$ do not change the contribution rate and then $T P F$, while $\theta$ produces an increase on $c(t)$ over the desirable level for few years and hence $T P F$ is close to zero.

Scenario $\mathrm{C}$ highlights the ABMs functioning when social adequacy accounts less than the contribution rate sustainability. Once again the ABMs including $\theta$ are the best ones.

Figures 12, 13 and 14 show the evolution of benefit ratio, UL ratio and contribution rate for all three $\mathrm{ABMs}$ for scenario $\mathrm{A}, \mathrm{B}$ and $\mathrm{C}$ respectively.

In scenario A (see Fig. 12), in order to increase the benefit ratio (panel a) and to guarantee the long term financial sustainability and the short term liquidity of the NDC system (panel b), the benefits indexation is almost always higher than in the no ABMs case (panel c), while the notional rate is reduced (panel d) and the value of contribution rate should increase up to the upper bound (panel e). Conversely, in scenario B (Fig. 13) the benefit ratio remains substantially unchanged respect to the no ABMs case (panel a). Concerning the UL ratio 


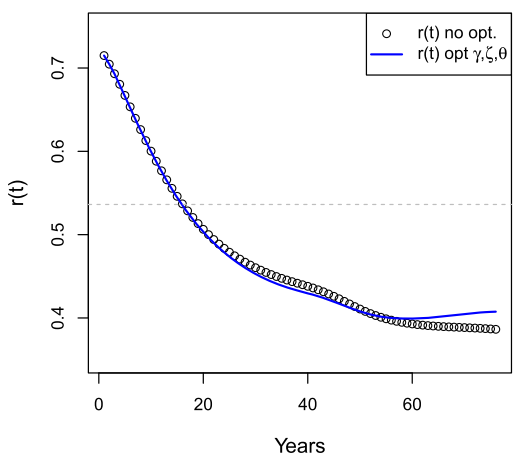

(a) Benefit ratio

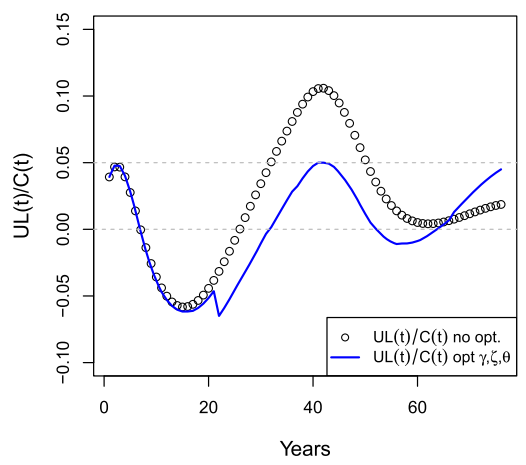

(b) Unfunded liabilities ratio

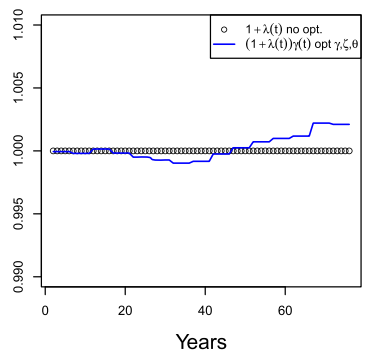

(c) Benefits indexation

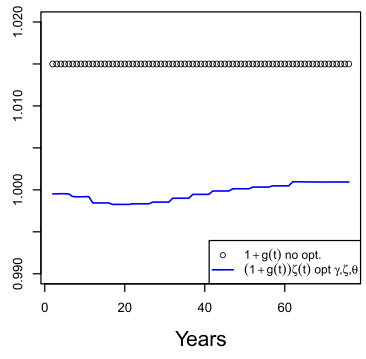

(d) Notional rate

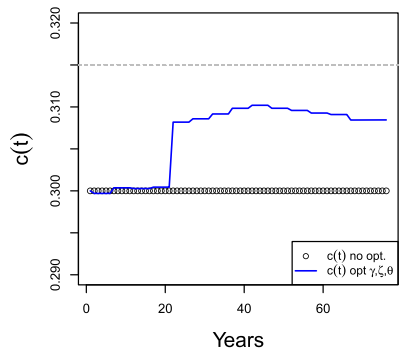

(e) Contribution rate

Fig. 13 Pension system evolution under the scenario $\mathrm{B}\left(\psi_{1}=0, \psi_{2}=1\right)$ with triple ABM

(panel b), the ABMs reduce the values but, at the same time, require a reduction on the notional rate (panel d) and a small rise in the contribution rate (panel e) for respecting the financial sustainability and liquidity constraints. Benefits indexation (panel c) remains substantially unchanged. Scenario C (Fig. 14) results to be a compromise between the base scenario (Fig. 8) and scenario B (Fig. 13) as a consequence of the penalty factors' choice. Respect to the base scenario, scenario $\mathrm{C}$ fails the adequacy target but the final benefit ratio is in this case higher than in scenario B (panel a). The benefits indexation in scenario $\mathrm{C}$ is higher than in scenario B (panel c), while the notional rate is smaller than in the base scenario (panel d). Otherwise, while in the base scenario the contribution rate exceeds the target level, in scenario $\mathrm{C}$ it lays below the threshold even if with higher values than in scenario $\mathrm{B}$ (panel e).

\section{Conclusions}

NDC systems have been introduced in order to confront the sustainability issues in traditional DB pension systems. While a NDC system can be financially sustainable in constant demographical and economic conditions, it may not be so in dynamic conditions. In such situation, adjustment mechanisms become necessary to assure the financial equilibrium. However, all the adjustments for NDC system proposed in the literature work on the level of present and future benefits (typically changing the notional rate and the indexation rate), without changing the contribution rate. This situation could lead to an impoverishment of pensioners, producing social adequacy issues. 


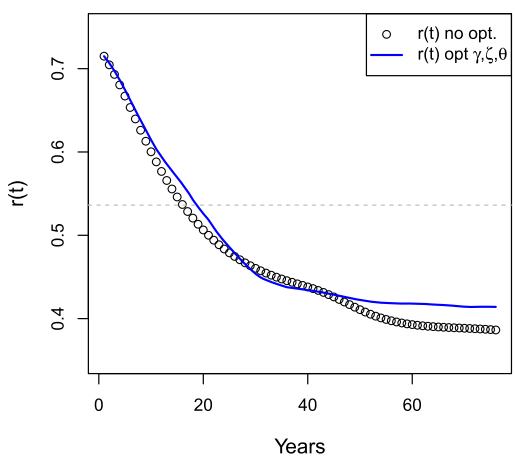

(a) Benefit ratio

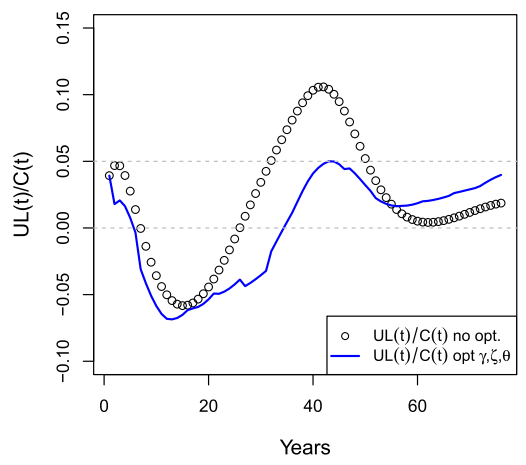

(b) Unfunded liabilities ratio

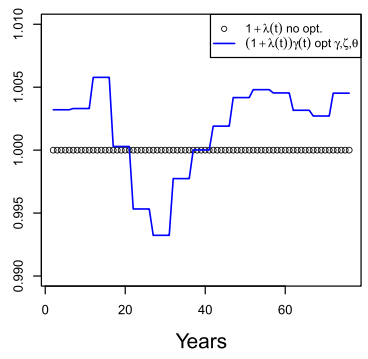

(c) Benefits indexation

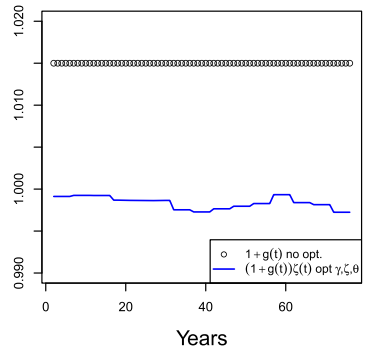

(d) Notional rate

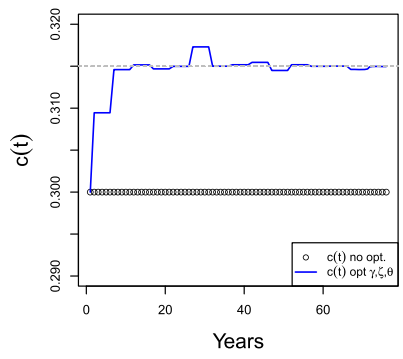

(e) Contribution rate

Fig. 14 Pension system evolution under the scenario $\mathrm{C}\left(\psi_{1}=0.25, \psi_{2}=0.75\right)$ with triple ABM

In this paper, we introduce within the NDC architecture ABMs that guarantee the social adequacy in accordance with the financial sustainability, by combining the expenditure reduction/increment with the variation over time of the contribution rate. The optimal ABM is obtained as a solution of a classical optimization problem by controlling the social adequacy of a NDC system under constraints on financial sustainability in the long run and short term liquidity. However, as too high contribution rate could produce negative effects on the labour market, the objective function also includes the contribution rate sustainability.

We consider different economic scenarios and different parameters for the objective function in order to monitor the change in the optimal paths of control variables (involving notional rate, indexation rate and contribution rate). In all the scenarios, every optimal solution satisfies the sustainability and liquidity constraints. Moreover, the introduction of a decision variable on contribution rate allows to obtain the best values for the objective function. This is more evident in the adverse economic scenarios, characterized by a stronger reduction of the benefit ratio over time, which poses a bigger adequacy issue. Therefore, we can state that when social adequacy is relevant, the $\mathrm{ABM}$ also including the contribution rate is more effective than those only involving present and future benefits. However, using the contribution rate as a control variable in a NDC system, where per definition the contribution rate is fixed, could be questionable and have limited applicability in a "canonical" NDC. Otherwise, operating only on notional rate and pension indexation does not allow to assure adequate pensions. Thus, in order to guarantee social adequacy, we assume that the contribution rate could change, defining this system as "Quasi-NDC". 
In conclusion, although our model has some limitations, it may serve as a useful tool for helping policy making. As any modeling, our final outcomes depend on the underlying data, assumptions and model's framework. In particular, they are strictly related to the definition of the target function to minimize as well as the constraints to fulfill. Further analyses could be carried out based on alternative definitions of social adequacy and financial constraints. Finally, our model has been developed in a deterministic environment, not taking into account the uncertainty concerning economic and demographic conditions. Future research could be dedicated to develop an ABMs in a stochastic environment, for example modeling the wage and the demographic processes as stochastic.

Funding Open access funding provided by UniversitA degli Studi di Roma La Sapienza within the CRUICARE Agreement.

Open Access This article is licensed under a Creative Commons Attribution 4.0 International License, which permits use, sharing, adaptation, distribution and reproduction in any medium or format, as long as you give appropriate credit to the original author(s) and the source, provide a link to the Creative Commons licence, and indicate if changes were made. The images or other third party material in this article are included in the article's Creative Commons licence, unless indicated otherwise in a credit line to the material. If material is not included in the article's Creative Commons licence and your intended use is not permitted by statutory regulation or exceeds the permitted use, you will need to obtain permission directly from the copyright holder. To view a copy of this licence, visit http://creativecommons.org/licenses/by/4.0/.

\section{A Appendix}

See Table 1.

Table 1 Main features of a NDC pension scheme. Example of Sweden, Italy, Latvia and Poland

\begin{tabular}{|c|c|c|c|c|}
\hline & Sweden & Italy & Latvia & Poland \\
\hline $\begin{array}{l}\text { Contribution } \\
\text { rate }\end{array}$ & $16 \%$ & $33 \%$ & $14 \%$ & $12.2 \%$ \\
\hline $\begin{array}{l}\text { Retirement } \\
\text { age }\end{array}$ & 65 & 65 & 66 & 65 \\
\hline Notional rate & $\begin{array}{l}\text { Rate of increase of } \\
\text { the mean } \\
\text { individual wage }\end{array}$ & $\begin{array}{l}\text { Average increase } \\
\text { on } 3 \text { years of the } \\
\text { GDP }\end{array}$ & $\begin{array}{l}\text { Rate of increase of } \\
\text { the total wages }\end{array}$ & $\begin{array}{c}\text { Rate of increase of } \\
\text { the total wages }\end{array}$ \\
\hline $\begin{array}{l}\text { Indexation of } \\
\text { the benefits }\end{array}$ & $\begin{array}{l}\text { Difference } \\
\text { between the } \\
\text { consumer price } \\
\text { index and } 1.6 \%\end{array}$ & $\begin{array}{l}\text { Consumer price } \\
\text { index }\end{array}$ & $\begin{array}{l}\text { Consumer price } \\
\text { index }\end{array}$ & $\begin{array}{l}\text { Combination of } \\
\text { the consumer } \\
\text { price index and } \\
\text { the wage } \\
\text { increase }\end{array}$ \\
\hline $\begin{array}{l}\text { Conversion } \\
\text { factor }\end{array}$ & $\begin{array}{l}\text { Life time annuity } \\
\text { computed with } \\
\text { an ex ante rate of } \\
\text { increase of } 1.6 \%\end{array}$ & $\begin{array}{l}\text { Life time annuity } \\
\text { computed with } \\
\text { an ex ante rate of } \\
\text { increase of } 1.5 \%\end{array}$ & Life expectancy & Life expectancy \\
\hline $\begin{array}{l}\text { Automatic } \\
\text { adjustment }\end{array}$ & Yes & No & No & No \\
\hline
\end{tabular}




\section{B Appendix}

See Tables 2, 3 and 4.

Table 2 Values of the total penalty function under different AMBs. Optimization parameters: $\psi_{1}=0.5$, $\psi_{2}=0.5, c_{1}=0.536, c_{2}=0.315, \varepsilon=0.001, u=0.05, G_{1}=Z_{1}=0.95, T_{1}=0.85, G_{2}=Z_{2}=1.05$, $T_{2}=1.15, g_{1}=z_{1}=0.99, t_{1}=0.95, g_{2}=z_{2}=1.01, t_{2}=1.05$

\begin{tabular}{|c|c|c|c|c|c|c|c|c|}
\hline \multirow[t]{2}{*}{ Factors } & \multirow[t]{2}{*}{ No ABMs } & \multicolumn{3}{|c|}{ One ABM } & \multicolumn{3}{|c|}{ Two ABMs } & \multirow{2}{*}{$\begin{array}{l}\text { Three ABMs } \\
\gamma^{*}(t), \quad \zeta^{*}(t), \\
\theta^{*}(t)\end{array}$} \\
\hline & & $\gamma^{*}(t)$ & $\zeta^{*}(t)$ & $\theta^{*}(t)$ & $\begin{array}{l}\gamma^{*}(t) \\
\zeta^{*}(t)\end{array}$ & $\begin{array}{l}\zeta^{*}(t) \\
\theta^{*}(t)\end{array}$ & $\begin{array}{l}\gamma^{*}(t), \\
\theta^{*}(t)\end{array}$ & \\
\hline TPF & 3.20 & 3.38 & 3.48 & 2.72 & 3.37 & 2.47 & 2.34 & 2.33 \\
\hline
\end{tabular}

Table 3 Values of the total penalty function under different AMBs and different economic scenarios. Optimization parameters: $\psi_{1}=0.5, \psi_{2}=0.5, c_{1}=0.536, c_{2}=0.315, \varepsilon=0.001, u=0.05, G_{1}=Z_{1}=0.95$, $T_{1}=0.85, G_{2}=Z_{2}=1.05, T_{2}=1.15, g_{1}=z_{1}=0.99, t_{1}=0.95, g_{2}=z_{2}=1.01, t_{2}=1.05$

\begin{tabular}{|c|c|c|c|c|c|c|c|c|}
\hline \multirow[t]{2}{*}{ Scenarios } & \multirow[t]{2}{*}{ No ABMs } & \multicolumn{3}{|c|}{ One ABM } & \multicolumn{3}{|c|}{ Two ABMs } & \multirow{2}{*}{$\begin{array}{l}\text { Three ABMs } \\
\gamma^{*}(t), \quad \zeta^{*}(t), \\
\theta^{*}(t)\end{array}$} \\
\hline & & $\gamma^{*}(t)$ & $\zeta^{*}(t)$ & $\theta^{*}(t)$ & $\begin{array}{l}\gamma^{*}(t), \\
\zeta^{*}(t)\end{array}$ & $\begin{array}{l}\zeta^{*}(t) \\
\theta^{*}(t)\end{array}$ & $\begin{array}{l}\gamma^{*}(t), \\
\theta^{*}(t)\end{array}$ & \\
\hline Base & 3.20 & 3.38 & 3.48 & 2.72 & 3.37 & 2.47 & 2.34 & 2.33 \\
\hline 2 & 4.67 & 5.06 & 5.18 & 4.42 & 5.05 & 4.34 & 4.23 & 4.21 \\
\hline 3 & 3.49 & 3.89 & 3.93 & 3.46 & 3.77 & 2.94 & 2.91 & 2.73 \\
\hline
\end{tabular}

Table 4 Values of the total penalty function under different weights of the penalty factors. Optimization parameters: $c_{1}=0.536, c_{2}=0.315, \varepsilon=0.001, u=0.05, G_{1}=Z_{1}=0.95, T_{1}=0.85, G_{2}=Z_{2}=1.05$, $T_{2}=1.15, g_{1}=z_{1}=0.99, t_{1}=0.95, g_{2}=z_{2}=1.01, t_{2}=1.05$. Base scenario: $\psi_{1}=0.5, \psi_{2}=0.5$, scenario A: $\psi_{1}=1, \psi_{2}=0$, scenario B: $\psi_{1}=0, \psi_{2}=1$, scenario C: $\psi_{1}=0.25, \psi_{2}=0.75$

\begin{tabular}{|c|c|c|c|c|c|c|c|c|}
\hline \multirow[t]{2}{*}{ Scenarios } & \multirow[t]{2}{*}{ No ABMs } & \multicolumn{3}{|c|}{ One ABM } & \multicolumn{3}{|c|}{ Two ABMs } & \multirow{2}{*}{$\begin{array}{l}\text { Three ABMs } \\
\gamma^{*}(t), \quad \zeta^{*}(t), \\
\theta^{*}(t)\end{array}$} \\
\hline & & $\gamma^{*}(t)$ & $\zeta^{*}(t)$ & $\theta^{*}(t)$ & $\begin{array}{l}\gamma^{*}(t) \\
\zeta^{*}(t)\end{array}$ & $\begin{array}{l}\zeta^{*}(t) \\
\theta^{*}(t)\end{array}$ & $\begin{array}{l}\gamma^{*}(t) \\
\theta^{*}(t)\end{array}$ & \\
\hline Base & 3.20 & 3.38 & 3.48 & 2.72 & 3.37 & 2.47 & 2.34 & 2.33 \\
\hline A & 6.40 & 6.76 & 6.97 & 4.86 & 6.74 & 3.05 & 2.79 & 2.78 \\
\hline B & 0 & 0 & 0 & 0.05 & 0 & 0 & 0 & 0 \\
\hline C & 1.60 & 1.69 & 1.74 & 1.48 & 1.68 & 1.46 & 1.45 & 1.43 \\
\hline
\end{tabular}




\section{References}

Alonso-García, J., Boado-Penas, M. D. C., \& Devolder, P. (2018). Automatic balancing mechanisms for notional defined contribution accounts in the presence of uncertainty. Scandinavian Actuarial Journal, 2, 85-108.

Battocchio, P., Menoncin, F., \& Scaillet, O. (2007). Optimal asset allocation for pension funds under mortality risk during the accumulation and decumulation phases. Annals of Operations Research, 152, 141-165.

Boado-Penas, M. D. C., Valdés-Prieto, S., \& Vidal-Meliá, C. (2008). The actuarial balance sheet for pay-asyou-go finance: Solvency indicators for Spain and Sweden. Fiscal Studies, 29(1), 89-134.

Boado-Penas, M. D. C., \& Vidal-Meliá, C. (2013). The actuarial balance of the PAYG pension system: The Swedish NDC model versus the DB-type models. In R. Holzmann, E. Palmer, \& D. Robalino (Eds.), NDC pension schemes in a changing pension world. Gender, politics, and financial stability (Vol. 2). Washington, DC: World Bank.

Chlon-Domińczak, A., Franco, D., \& Palmer, E. (2012). The first wave of NDC reforms: The experiences of Italy, Latvia, Poland and Sweden. In R. Holzmann, E. Palmer, \& D. Robalino (Eds.), NDC pension schemes in a changing pension world. Progress, lessons, and implementation (Vol. 1). Washington, DC: World Bank.

D’Addio, A. C., \& Whitehouse, E. (2012). Towards financial sustainability of pensions systems: The role of automatic adjustment mechanisms in OCDE and EU countries (Vol. 8(12)). Bern: Bundesmat fur Sozialversicherungen.

Devolder, P., \& de Valeriola, S. (2019). Between DB and DC: Optimal hybrid PAYG pension schemes. European Actuarial Journal, 9(2), 463-482.

Gannon, F., Legros, F.,\& Touzé, V. (2015). Automatic adjustment mechanisms and budget balancing of pension schemes. Working paper.

Godinez-Olivares, H., Boado-Penas, M. C., \& Haberman, S. (2016). Optimal strategies for pay-as-you-go finance: A sustainability framework. Insurance Mathematics and Economics, 69, 117-126.

Gronchi, S., \& Nisticò, S. (2006). Implementing the NDC theoretical model: A comparison of Italy and Sweden. In R. Holzmann \& G. Palmer (Eds.), Pension reform: Issues and prospect for non-financial defined contribution (NDC) schemes, chapter 19 (pp. 493-515). Washington, DC: World Bank.

Holzmann, R. (2017). The ABCs of nonfinancial defined contribution (NDC) schemes. International Social Security Review, 70(3), 53-77.

Iyer, S. (1999). Actuarial mathematics of social security pensions. Geneva: International Labour Office and International Social Security Association.

Johnson, S. G. (2010). The NLopt nonlinear-optimization package. http://cran.r-project.org/package=nloptr.

Klein Haneveld, W. K., Streutker, M. H., \& van der Vlerk, M. H. (2010). An ALM model for pension funds using integrated chance constraints. Annals of Operations Research, 177, 47-62.

Knell, M. (2010). How automatic adjustment factors affect the internal rate of return of PAYG pension systems. Journal of Pension Economics and Finance, 9(1), 1-23.

Knell, M., Kohler-Toglhofer, W., \& Prammer, D. (2006). The Austrian pension system-How recent reforms have changed fiscal sustainability and pension benefits. Monetary Policy and Economy, Q2(06), 69-93.

Kopa, M., Moriggia, V., \& Vitali, S. (2018). Individual optimal pension allocation under stochastic dominance constraints. Annals of Operations Research, 260, 255-291.

Musgrave, R. (1981). A reappraisal of social security finance. Social Security financing (pp. 89-127). Cambridge: MIT.

OECD. (2017). Pensions at a glance 2017: OECD and G20 indicators. Paris: OECD Publishing. https://doi. org/10.1787/pension_glance-2017-en.

Palmer, E. (2006). What's NDC? In R. Holzmann \& E. Palmer (Eds.), Pension reform: Issues and prospects for non-financial defined contribution (NDC) schemes, chapter 2 (pp. 17-35). Washington, DC: The World Bank.

Powell, M. J. D. (1994). A direct search optimization method that models the objective and constraint functions by linear interpolation. In S. Gomez \& J. P. Hennart (Eds.), Advances in optimization and numerical analysis (pp. 51-67). Dordrecht: Springe. ISBN 978-90-481-4358-0.

Ragioneria Generale dello Stato (RGS). (2018). Le tendenze di medio-lungo periodo del sistema pensionistico e socio-sanitario - Aggiornamento 2018. Report, 19, Rome.

Schokkaert, E., Devolder, P., Hindriks, J., \& Vandenbroucke, F. (2018). Towards an equitable and sustainable points system. A proposal for pension reform in Belgium. Journal of Pension Economics and Finance. https://doi.org/10.1017/S1474747218000112.

Settergren, O. (2001). The automatic balance mechanism of the Swedish pension system-A non-technical introduction. Wirtschaftspolitische Blätter, 4, 339-349. 
Valdés-Prieto, S. (2000). The financial stability of notional account pensions. Scandinavian Journal of Economics, 102(3), 395-417. https://doi.org/10.1111/1467-9442.03205.

Vidal-Meliá, C., Boado-Penas, M. D. C., \& Settergren, O. (2009). Automatic balance mechanisms in pay-asyou-go pension systems. The Geneva Papers on Risk and Insurance Issues and Practice, 34(2), 287-317.

Vidal-Meliá, C., Boado-Penas, M. D. C., \& Settergren, O. (2010). Instruments for improving the equity, transparency and solvency of payg pension systems. NDCs, ABs and ABMs. In M. Micocci, G. Gregoriou, \& G. B. Masala (Eds.), Pension fund risk management. Financial and actuarial modelling, chapter 18 (pp. 419-473). New York: Chapman and Hall. ISBN 1439817520.

Ypma, J. (2018). nloptr: R interface to NLopt. http://cran.r-project.org/web/packages/nloptr/index.html.

Publisher's Note Springer Nature remains neutral with regard to jurisdictional claims in published maps and institutional affiliations. 